\title{
The 5'-NAD cap of RNAIII modulates toxin production in Staphylococcus aureus isolates.
}

\author{
1 Hector Gabriel Morales-Filloy ${ }^{1}$, Yaqing Zhang ${ }^{1}$, Gabriele Nübel ${ }^{1}$, Shilpa Elizabeth George ${ }^{2}$, \\ 2 Natalya Korn ${ }^{2}$, Christiane Wolz ${ }^{2}$, Andres Jäschke ${ }^{1^{*}}$ \\ $3{ }^{1}$ Institute of Pharmacy and Molecular Biotechnology (IPMB), Heidelberg University, Heidelberg, \\ 4 Germany \\ $5 \quad{ }^{2}$ Interfaculty Institute of Microbiology and Infection Medicine, University of Tübingen, Tübingen, \\ 6 Germany \\ $7 \quad *$ Correspondence: \\ 8 Prof. Dr. Andres Jäschke \\ 9 jaeschke@uni-hd.de
}

101 Abstract

11 Nicotinamide adenosine dinucleotide (NAD) has been found to be covalently attached to the $5^{\prime}$ 12 ends of specific RNAs in many different organisms, but the physiological consequences of th is 13 modification are largely unknown. Here we report the occurrence of several NAD-RNAs in the 14 opportunistic human pathogen Staphylococcus aureus. Most prominently, RNAIII, a central 15 quorum-sensing regulator of this bacterium's physiology, was found to be 5'-NAD-capped to a 16 significant extent. NAD incorporation efficiency into RNAlll was found to depend in vivo on the 171 position of the P3 promoter. Reduction of RNAIII's NAD content led to a decreased expression 18 of alpha- and delta-toxins, resulting in reduced cytotoxicity of the modified strains. These effects 19 to not seem to be due to changes in RNAIII's secondary structure upon NAD attachment, as 20 indicated by largely unaltered patterns in in vitro chemical probing experiments. Our study 21 represents a large step towards establishing a biological function of the 5'-NAD cap, which for 22 RNAIII in S. aureus is to modulate the expression of virulence factors.

\section{Importance}

24 Numerous organisms, including bacteria, are endowed with a 5'-NAD cap in specific RNAs. While 25 the presence of the 5'-NAD cap modulates the stability of the modified RNA species, a significant 26 biological function and phenotype have not been assigned so far. Here, we show the presence of a 5'-NAD cap in RNAlll from $S$. aureus, a dual-function regulatory RNA involved in quorum-sensing processes and regulation of virulence factor expression. We also demonstrate that altering the natural NAD modification ratio of RNAIII leads to a decrease in exotoxin production, thereby modulating bacterium's virulence. Our work unveils a new layer of regulation of RNAIII and the agr system that might be linked to the redox state of the NAD molecule in the cell.

\section{Introduction}

33 The discovery of the nicotinamide adenosine dinucleotide (NAD) bacterial 5'-cap in regulatory 34 RNAs in Escherichia coli (Cahová, Winz, Höfer, Nübel, \& Jäschke, 2015) challenged a long-standing 35 dogma. To date, the 5'-NAD cap has been reported in Gram-negative and Gram-positive (Bacillus 
subtilis (Frindert et al., 2018)) bacteria as well as in eukaryotes such as Saccharomyces cerevisiae (Kellner et al., 2014; Walters et al., 2017), the mammalian cell line HEK293T (Jiao et al., 2017) and plants from the genus Arabidopsis (Wang et al., 2019; Zhang et al., 2019). This novel nucleotide modification in RNA appears to be present in most organisms if not ubiquitous. However, no NAD-modified RNA has been reported in pathogens yet. The opportunistic pathogen Staphylococcus aureus is a gram-positive bacterium responsible for the majority of nosocomial infections (David \& Daum, 2010). After the invasion of host tissue, S. aureus can cause bacteremia, sepsis, endocarditis, and toxic shock syndrome (Lowy, 1998). The pathogenicity of $S$. aureus is strongly related to the expression of numerous virulence factors, many of which are under the control of the agr quorum-sensing system (Bronesky et al., 2016; Quave et al., 2016; Traber et al., 2008). The agr locus harbours two promoters (P2 and P3) located back to back in the chromosome (Janzon, Lofdahl, \& Arvidson, 1989; Peng, Novick, Kreiswirth, Kornblum, \& Schlievert, 1988) (Figure 1A). P3 encodes a regulatory RNA (RNAIII) that additionally contains a small open reading frame (ORF) for delta-toxin (HId) (Janzon \& Arvidson, 1990; Novick et al., 1993), whereas P2 regulates the transcription of a polycistronic RNA (RNAll) that encodes the Agr proteins Agr A/B/C/D (Figure 1A) (Novick et al., 1995). With this quorum-sensing mechanism, $S$. aureus senses the cell density based on the extracellular concentration of the self-produced autoinducer peptide (AIP) (Recsei et al., 1986). The AIP binds to the AgrC histidine kinase membrane receptor and activates AgrA regulator by phosphorylation (Figure 1A). AgrA P activates transcription of the $\mathrm{P} 2$ and $\mathrm{P} 3$ promoters, producing RNAll and RNAIII, respectively (Figure 1A) (Bronesky et al., 2016; Koenig, Ray, Maleki, Smeltzer, \& Hurlburt, 2004). AgrA P furthermore activates transcription of phenol-soluble modulins (psm $\alpha$ and psmb) (Queck et al., 2008), which are small peptides with surfactant activity that contribute to cell membrane disruption and therefore to S. aureus cytotoxicity (M. Li et al., 2009; Peschel \& Otto, 2013). RNAIII plays a crucial bifunctional role in the switch from the adhesion phase towards invasion (Bronesky et al., 2016; Koenig et al., 2004), which ultimately determines the infective behaviour of the bacterium. On the one hand, it inhibits translation of rot mRNA, which encodes for a repressor (Rot) that blocks the transcription of several toxins (Boisset et al., 2007; Geisinger, Adhikari, Jin, Ross, \& Novick, 2006; Said-Salim et al., 2003). Also, RNAlll represses the expression of surface proteins, e.g., protein A or coagulase through an antisense mechanism (Boisset et al., 2007; Bronesky et al., 2016; Huntzinger et al., 2005). On the other hand, it activates the production of several hemolytic toxins, such as alpha-toxin (Hla) (Morfeldt, Taylor, von Gabain, \& Arvidson, 1995) and the self-encoded HId. The addition of the canonical N7-methyl guanosine $\left(\mathrm{m}^{7} \mathrm{G}\right)$ cap to the $5^{\prime}$-ends of eukaryotic mRNAs proceeds co-transcriptionally once the transcript has reached a length of 25 nucleotides. The NAD cap is, however, incorporated in a different way in prokaryotes and probably in all organisms: the ubiquitous redox coenzyme NAD is incorporated as the very first nucleotide $a b$ initio) into RNA during transcription initiation by the RNA polymerase, acting as a non-canonical initiating nucleotide (NCIN) that competes with ATP at A-initiating promoters (Bird et al., 2016; Frindert et al., 2018). Thus, transcription appears to constitute the primary source of 5'-NADRNAs in the cell. NAD incorporation into RNA has furthermore been demonstrated to strongly depend on the promoter sequence around the transcription start site (TSS) (Frindert et al., 2018;

78 Vvedenskaya et al., 2018). In E. coli and B. subtilis, the -1 position turned out to be the most 79 important one for NAD incorporation, likely due to pseudo-base-pairing between the 
nicotinamide moiety of NAD and the nucleotides at the -1 position of the DNA non-coding strand (thymidine (T) and cytidine (C)) (Vvedenskaya et al., 2018). The functions of the NAD cap are not yet fully understood, but in prokaryotes, it seems to confer stability to RNA. In E. coli, the NAD cap protects RNA against 5'-processing by the RNApyrophosphohydrolase (RppH) and thereby against RNaseE degradation (Cahová et al., 2015), whereas in B. subtilis, it stabilises RNA against exoribonucleolytic attack by RNase J1 (Frindert et al., 2018). Furthermore, E. coli possesses an NAD-decapping machinery based on the Nudix phosphohydrolase NudC (Frick \& Bessman, 1995), which efficiently hydrolyses the NAD cap and leaves a 5'-monophosphate RNA (p-RNA) (Cahová et al., 2015). Despite Nudix hydrolase motifs being present in several enzymes of $S$. aureus, no NudC ortholog has been found to date. In mammalian cells, the NAD-decapping machinery works in a very different way. The DXO enzymes first remove the entire NAD cap from an mRNA (releasing NAD and $p-R N A$ ) and then proceed with exonucleolytic mRNA decay (Jiao et al., 2017). In this study, we reveal by NAD captureSeq the presence of NAD-capped mRNAs and regulatory RNAs in the opportunistic pathogen $S$. aureus. The highly expressed, multifunctional, proteincoding, and regulatory RNA, RNAllI, is found to bear the NAD cap. Additionally, we study the importance of the -1 and +1 positions of the P3 promoter for the incorporation of NAD into RNAIII in vivo. Finally, we also investigate the consequences of changing RNAIII's NAD modification ratio on $S$. aureus virulence. The obtained results are interpreted in the context of the current knowledge of $S$. aureus's pathobiology.

\section{Results}

\subsection{S. aureus possesses NAD-capped RNAs.}

102 To detect and quantify NAD-capped RNAs in S. aureus, Liquid Chromatography coupled with Mass Spectrometry (LC-MS) analysis of total RNA samples was carried out. Two RNA samples from $S$. aureus ATCC 25923 were washed extensively to remove contaminating free NAD before enzymatic treatment with $E$. coli NudC and alkaline phosphatase. Upon this treatment, NAD-RNAs will liberate $\mathrm{N}$-ribosylnicotinamide ( $\mathrm{r}-\mathrm{NA}$ ) that can be sensitively detected by MS analysis. The results revealed an average amount of $25.25 \pm 1.64 \mathrm{fmol}$ of NAD-RNA per microgram of RNA, which corresponds to an estimated amount of $897 \pm 58$ NAD-RNA molecues per cell (Table S1) (Chen, Kowtoniuk, Agarwal, Shen, \& Liu, 2009). These results indicated the presence of NADcapped RNAs in S. aureus. In order to identify NAD-capped RNAs, NAD captureSeq was performed (Winz et al., 2017) Total RNA from S. aureus ATCC 25923 (isolated at the late exponential phase) was treated per duplicate either with ADP-ribosyl cyclase (ADPRC), allowing selective biotinylation of NAD-RNA, or mocktreated (minus ADPRC control). The captured RNAs were reverse transcribed and PCR-amplified to generate a DNA library for Illumina sequencing (Figure S1A). The distribution of the obtained normalised mapped reads revealed $96.87 \%$ mRNAs, $2.46 \%$ tRNAs, and $0.68 \%$ rRNAs with enrichment values up to 50-fold. Enriched hits $(P<0.05$, log2-fold change $>2$, base mean $>10)$

were visualised with the Integrated Genome Browser (Nicol, Helt, Blanchard, Raja, \& Loraine, $1192009)$ to identify reads that clustered at the $5^{\prime}$-ends of transcripts initiating with adenosine $(+1 \mathrm{~A})$ 120 (Figure 1B). 67.7\% of the initial enriched hits (21 out of 31) had these properties (Table S2) and 
121 are indicated as green dots in the upper right sector of the scatter plot (Figure 1B). The TSS 122 analysis of the enriched hits showed $\mathrm{T}(61.9 \%)$ or $\mathrm{A}(28.6 \%)$ at position -1 of the promoter 123 predominantly. $\mathrm{G}$ or $\mathrm{T}$ usually occupy the +2 position with the same occurrence (33.3\%) whereas $124+3$ position is dominated by $\mathrm{A}(57.1 \%)$. The predominant nucleobase at position -3 and -2 of the 125 promoter was A (71.4\% and $47.6 \%$ respectively, Figure S1B). Most enriched RNAs turned out to 126 be mRNA 5'-fragments (Table S2). However, the most abundant and the most enriched hit was 127 the bifunctional RNAIII ( $h / d /$ RNAIll gene, Figure 1B, green star). Notably, the other transcript from 128 the agr locus, RNAll, which has a similar promoter and is reported to also initiate with A (Novick 129 et al., 1995; Reynolds \& Wigneshweraraj, 2011), was not enriched at all (Figure 1B, red star).

\section{$130 \quad 4.2$ The multifaceted regulatory RNAllI contains a 5'-NAD cap.}

131 The obtained reads for hld/RNAlll gene mapped clearly on its 5'-UTR (Figure 1C). As NAD 132 captureSeq does not use a fragmentation step and size-selects (at the very end, after PCR 133 amplification) amplicons that correspond to RNAs $<\sim 170 \mathrm{nt}$, information about full-length mRNA 134 species cannot be obtained from these data. To quantitatively investigate the length distribution 135 of NAD-RNAIII, qPCR was performed on the enriched cDNA obtained directly from reverse 136 transcription, before any amplification or size fractionation using gene-specific primers (Table S3) 137 targeting different regions of RNAIII, thereby comparing the cDNA from the NAD captureSeq 138 sample with the mock-treated negative control. The qPCR data revealed the most substantial 139 enrichment for the 5 '-end region, but a significant presence and enrichment of full-length RNAIII 140 (Figure 1D). Northern blot analysis (which is independent of the nature of the $5^{\prime}$-end) indicated 141 that overall, RNAIII in S. aureus is predominantly full-length (Figure S1C).

142 To confirm that the NAD is covalently linked to RNAlll's 5'-end, RNAIII (enriched) and 5SrRNA 143 (non-enriched, negative control) were specifically isolated from S. aureus total RNA by pull-down 144 using biotinylated complementary oligonucleotides. Afterwards, RNAs were quantified, treated 145 with NudC and alkaline phosphatase, and the small-molecule fraction analysed by LC-MS (Figure $146 \mathrm{1E})$. This analysis revealed an intensive peak corresponding to nicotinamide $(\mathrm{m} / \mathrm{z}=122.81$, 147 originating from $r-N A, m / z=254.94$ ) in the case of RNAIII, whereas for 5SRNA the same peak 148 could only be detected at 24-fold higher input RNA concentration (Figure 1F). The NAD 149 modification ratio, i.e., the percentage of molecules of that RNA species that carry the 5'-NAD150 modification, of RNAIII and 5SrRNA was calculated as $36.20 \%$ and $0.25 \%$, respectively (Figure 1F).

\subsection{Guanosine at position -1 of the P3 promoter increases NAD incorporation into RNAIII in vivo.}

153 To investigate the biological consequences of $5^{\prime}$-NAD modification in vivo, $S$. aureus strains that 154 differ strongly in their content of $5^{\prime}$-NAD-RNAIII, with as little as possible differences in the 155 transcriptome, had to be generated. Toward this end, we complemented a strain devoid of the $156 \mathrm{hld} / \mathrm{RNAlll}$ gene (S. aureus HG001 $\triangle R N A I I I)$ with plasmids based on the shuttle vector pCG-246 157 (Helle et al., 2011). These plasmids carried the hld/RNAll gene behind different promoters: pCG158 P3 carried the native P3 promotor, while pCG-P3(-1G) had a mutated version of this promoter ($1591 \mathrm{~T}$ to $-1 \mathrm{G})$. To unravel whether the lack of NAD captureSeq enrichment of RNAll was due to 160 properties of its promoter, construct PCG-P2 was generated in which the P2 promoter controlled 
161 the RNAlll native sequence (Figure 2A). Unlike the previously used S. aureus ATCC 25923, in the generated strains the $h / d /$ RNAll gene is located on a plasmid.

163 To detect variations in RNAIll's modification ratio, we analysed RNAlll pulled down from total RNA from the RNAlll-complemented $S$. aureus strains by acryloaminophenyl boronic acid (APB) gel electrophoresis that separates 5'-NAD-RNA from 5'-p and 5'-ppp-RNA, combined with Northern blot (Alwine, Kemp, \& Stark, 1977; Igloi \& Kossel, 1985; Nübel, Sorgenfrei, \& Jäschke, 2017). As the full-length RNAllI was too long for efficient separation and precise quantification (Figure S1D), a pre-treatment with a designed DNAzyme was introduced which cleaved RNAIII to yield 125 nt 5 '-terminal fragments (Figure 2B). The strains containing pCG-P2 showed no NAD incorporation into the RNAIII transcript at all, whereas RNAIII in pCG-P3 and pCG-P3(-1G)transformed strains showed an average NAD-modification ratio of $9.82 \pm 0.15 \%$ and $24.91 \pm$ $0.37 \%$, respectively (Figure $2 \mathrm{C}$ ). Indeed, S. aureus pCG-P(-1G) was found to have a significantly higher amount of NAD-RNAlll than $S$. aureus pCG-P3 ( $t$-test; $P<0.0001$ ), demonstrating the importance of the -1 mutation on NAD incorporation efficiency, which confirms findings in other microorganisms (Frindert et al., 2018; Vvedenskaya et al., 2018). In all RNAIll samples, the slowermigrating band disappeared upon treatment with $E$. coli NudC, further supporting the nature of the $5^{\prime}$-modification as NAD (Figure $2 \mathrm{C}$ ).

178 To test whether this different NAD modification percentage in the three RNAlll constructs (pCGP3, pCG-P2, pCG-P3(-1G)) is also reflected in NAD captureSeq enrichment, we had to modify the analysis to allow quantitative comparisons between different RNA species by adding pure NADRNA spike-in controls of five different lengths as internal standards (IS; 61, 104, 205, 302 and 400 $\mathrm{nt}$, Table S4) to allow for normalization. The NGS results revealed that the NAD capture efficiency of the IS between the samples was very similar (Figure 2D, one-way ANOVA; $P=0.8617$ ). When comparing the hld/RNAlll enrichment in the different $S$. aureus strains, pCG-P3(-1G) (log2FoldChange $=3.57$ ) showed higher enrichment than S. aureus pCG-P3 (log2FoldChange = 2.77). In the case of $S$. aureus pCG-P2, no enrichment was found for hld/RNAlll (log2FoldChange $=0.48$ ). Thus, the NGS data support the results obtained by APBgel - Northern blot analysis and confirm that a $-1 G$ in the P3 promoter significantly enhances NAD incorporation into RNAIII ( $t$ test; $P=0.036$, Figure $2 \mathrm{E}$ ). Analysis of the NAD captureSeq data from the three mutant strains

190 revealed a similar pattern of NADylation as in the ATCC 25923 wild type strain (Table S5, Table 191 S6 and Table S7). For pCG-P3 we obtained 11 enriched hits (4 of them common with the wild 192 type), in pCG-P3(-1G) 12 (4 commons), and pCG-P2 6 (3 commons).

\section{$193 \quad 4.4$ The TSS of the P2 promoter is guanosine.}

194 We were puzzled by the observation that RNAIII from strain pCG-P2 seemed to contain no NAD 195 at all. Sanger sequencing data after CRT-PCR (Slomovic \& Schuster, 2013), however, provided a 196 straightforward explanation: the transcription start site of the P2 promoter was a G instead of 197 the previously reported A (Novick et al., 1995; Reynolds \& Wigneshweraraj, 2011), and NAD does 198 not compete with GTP in transcription initiation. The analysis of 96 sequencing reactions (96 199 single colonies from each strain) from S. aureus pCG-P3 and pCG-P2 yielded well-defined 3' and $200 \quad 5^{\prime}$ ends of RNAIII, where the RNAllI's first nucleotide was $+1 \mathrm{~A}$ when transcribed from the P3 201 promoter, and $+1 G$ in the case of the P2 promoter (Figure 2F). A +1G was also found in RNAll (a 
natural product of P2 promoter) from S. aureus HG001 wild type strain after the analysis of 10 Sanger sequencing reactions (10 single colonies, Figure $2 \mathrm{~F}$ ).

\subsection{The 5'-NAD cap of RNAIII affects Hla and HId expression levels and thereby S. aureus's cytotoxicity.}

To study the accessibility of its NAD-5'-end, ${ }^{32} \mathrm{P}$-body-labelled pure NAD-RNAIII was subjected to in vitro cleavage with $E$. coli NudC. After 20 min of incubation at $37^{\circ} \mathrm{C}$, NudC had decapped $~ 65 \%$ of the RNAs, and this value did not change upon further incubation (up to 1 hour, Figure 3A). An additional unfolding-folding cycle, followed by the addition of fresh NudC, increased decapping to $\sim 83 \%$ (Figure $3 \mathrm{~A}$ ), suggesting that a fraction of NAD-RNAlll exists in a structure that is not susceptible to NudC cleavage, e.g., with the $5^{\prime}$-end involved in a double-strand (Höfer, Abele, Schlotthauer, \& Jäschke, 2016). To test the effect of the promoter mutations on the biosynthesis rate of RNAIII, a qPCR assay was performed with cDNA from the different $S$. aureus strains (total RNA harvested in late exponential phase and reverse transcribed). The assay revealed no significant difference in RNAIII content between pCG-P3 and pCG-P3(-1G) strains ( $t$-test; $P=0.1221$, Figure 3B). On the other hand, pCG-P2 showed a significantly lower amount of RNAlll than pCG-P3 ( $t$-test; $P=0.0276$, Figure 3B). Strains pCG-P3 and P3(-1G) differ only in one nucleotide, the -1 position of the P3 promoter, which leads to the same RNAIII transcript, just with different NAD modification levels. To test the influence of this single mutation on the transcriptome; RNA-Seq was performed on total RNA from both strains. Their transcriptomes were found to be very similar to each other, with only 4 upregulated genes ( $s p / A, s p / B, s p / C, s p / D$, all of them coding for serine proteases, Table S8) and 2 downregulated genes ( $s p a$, an uncharacterized gene with homology to $s s a A$, Table S8) in $S$. aureus pCG-P3(-1G). The spIABCD operon is known to be activated via RNAIII, whereas spa is known to be inhibited by RNAIII (Queck et al., 2008). Thus, the higher NADylation in pCG-P3(-1G) might enhance RNAIII's inhibitory activity. Interestingly, the prototypic RNAlll target gene, hla, was neither upregulated nor downregulated in the RNA-Seq data. Hence, we speculated that NADylation of RNAIII may influence the translation of Hla, and therefore, an analysis of Hla abundance in culture supernatants was conducted. The Hla obtained in culture filtrates of $S$. aureus pCG-P3(-1G) was significantly lower than in S. aureus pCG-P3 in late exponential phase cultures ( $t$-test; $P=0.0148$, Figure $3 C$ and Figure S1E). Thus, $5^{\prime}-N A D$ capping of RNAll might modulate the interaction between the $5^{\prime}$-UTRs of RNAIll and hla mRNA as well, leading to a lower translation of the latter RNA. HId. According to LC-MS of culture filtrates, half the amount of HId was found in pCG-P3(-1G) (with the higher amount of 5'-NAD cap) compared to pCG-P3 (Figure 3C, Figure S1F). This finding indicates that RNAIII's 5'-NAD cap might impair hld mRNA translation. A decreased production of two major hemolytic toxins, Hla and HId, should lead to a less cytotoxic $S$. aureus strain. Indeed, an assay with $S$. aureus pCG-P3 and pCG-P3(-1G) culture supernatants in a human THP1 macrophage line (Figure 3D) revealed a significantly reduced cytotoxicity of pCG-P3(-1G) compared to pCG-P3 (Tukey's multiple comparisons-test; $P=0.0004$ ). 


\subsection{HId's Shine-Dalgarno sequence is accessible in vitro regardless of the presence of a 5'- NAD cap.}

In order to analyse whether 5'-NAD capping of RNAllI affects the secondary structure of its $5^{\prime}$ domain, we performed Selective 2'-Hydroxyl Acylation and Primer Extension (SHAPE) (Weeks \& Mauger, 2011; Wilkinson, Merino, \& Weeks, 2006). SHAPE is an approach to probe the structure of every nucleotide within an RNA simultaneously. The SHAPE reagent chemically modifies (acylates) the 2'-OH position of flexible nucleotides (Wilkinson et al., 2006). A subsequent DNA synthesis by reverse transcriptase stops one nucleotide before the position of a modified 2'ribose position, reporting the site of a SHAPE modification in the RNA (Weeks \& Mauger, 2011; Wilkinson et al., 2006). 1-methyl-7-nitro-isatoic anhydride (1M7) was chosen as SHAPE reagent (Mortimer \& Weeks, 2007). To determine whether RNAll's secondary structure is modulated by the nature of its 5'-end, pure 5'-NAD-RNAIII and ppp-RNAIII were required. Pure full-length (514 nt) NAD-RNAlll could not be prepared, as no method exists for its preparative separation from full-length ppp-RNAIll. Therefore, we first probed a shorter version of RNAlll consisting of nucleotides 1 to 113, designated as RNAIII leader, which could be prepared by in vitro transcription and APB-gel purification as pure NAD-capped (NAD-RNAlll leader), or pure triphosphorylated version (ppp-RNAlll leader). To exclude the possibility that the truncated RNAIII leader sequences fold differently than the full-length RNAIII, we compared in a second step pure full-length ppp-RNAlll with impure full-length NAD-RNA (containing NAD-RNA and pppRNA 1:1). The SHAPE data showed very similar nucleotide reactivity profiles for NAD-RNAIII leader and ppp-RNAIII leader (Figure 4A, Figure 4B and Figure S1G), indicating an accessible SD sequence regardless of their 5 '-end modification. When shaping full-length ppp-RNAIII and the ppp-/NAD-RNAllI mixture, both the overall SHAPE reactivity profile and SD's accessibility were similar to that of the ppp-RNAIII leader (Figure 4C, Figure 4D)

\section{Discussion}

\subsection{A short, regulatory, and protein-coding NAD-capped RNA in S. aureus.}

In this study, we have demonstrated the existence of 5'-NAD-capped RNAs in the opportunistic pathogen S. aureus. Since the discovery of the prokaryotic NAD cap in 2015, the presence of NADRNAs in many different organisms has been confirmed, and this modification might be ubiquitous. Nevertheless, the biological function of the $5^{\prime}$-NAD cap in prokaryotes is still unclear. In the case of $B$. subtilis, also a gram-positive bacterium, the NAD cap stabilises RNA against exoribonucleolytic attack by RNase J1 in vitro (Frindert et al., 2018). As in other organisms (Cahová et al., 2015; Frindert et al., 2018), several mRNAs were found to be enriched in the NAD captureSeq of S. aureus ATCC 25923. Most of these mRNAs encode proteins involved in different cellular processes: redox reactions, membrane transport, biosynthesis-related enzymes, phosphatases, kinases, and hydrolases (Table S2). Similar classes were observed in the S. aureus mutant strains (pCG-P3, pCG-P3(-1G) and pCG-P2), with several hits common with the wild type ATCC 25923 strain, i.e., NADP reductases, synthetases, and transcription factors.

Interestingly, the mutant-specific hits encoded for proteins that were similar to the ones found in the wild type strain, especially reductases such as the peptide methionine sulfoxide reductase 
or redox enzymes like the superoxide dismutase (Table S5, Table S6 and Table S7). Of particular interest is the enrichment of mRNAs that encode for NAD- NADP-utilizing enzymes (2dehydropantoate 2-reductase, L-lactate dehydrogenase). A similar observation has been made in B. subtilis, where L-threonine 3-dehydrogenase ( $t d h)$ was enriched (Frindert et al., 2018). These findings underpin the possibility that some NAD-mRNAs might act as a cofactor of their encoded enzyme. Moreover, the NAD cap could act as an enzyme-binding site to its mRNA as an additional regulatory mechanism (Jaschke, Hofer, Nubel, \& Frindert, 2016). However, the existence of this feedback mechanism still needs to be demonstrated empirically. The hld/RNAlll gene was by far the most enriched of all hits. The results showed a higher NAD modification level of RNAIII in the wild type strain ( 36\%) compared to pCG-P3 ( 10\%). This phenomenon might be due to the different S. aureus strains used (ATCC 25923 and plasmidcarrying HG001) although these values were obtained by different approaches (LC-MS vs Northern blot). The variation in NAD content is supported by a different hld/RNAlll enrichment in NAD captureSeq between both strains after, with a higher value obtained in ATCC 25923 (Table S2, Table S5). Furthermore, a distinct NAD modification level on RNAIll could be the cause of some differences in the infective behaviour between the strains. Nevertheless, RNAlll is still strongly NAD-modified whenever transcribed by P3 promoter, and this together with its high expression level, its role as a crucial intracellular effector of the quorum-sensing system, and the additional presence of an embedded ORF for the hld gene (Figure 1A) make RNAIII a promising candidate for unveiling a biological function of the NAD cap.

\subsection{The P3 promoter acts as a driver of NAD incorporation.}

The -1 position of the P3 promoter is found to modulate the incorporation of NAD into the nascent RNAIII. We also tested the effect of a promoter exchange on NAD transcriptional incorporation. The other promoter of the agr locus, P2, seems not to be prone to introduce NAD into RNAll (Log2FC $=-1.65$ in NAD captureSeq). These two promoters share several characteristics: phosphorylated AgrA activates transcription of both, they have a suboptimal interspace region between the -35 and -10 boxes, and both have been predicted to initiate with $\mathrm{a}+1 \mathrm{~A}$ (Novick et al., 1995; Reynolds \& Wigneshweraraj, 2011). Placing the P2 promoter upstream of the RNAlll sequence led to the total abolishment of NAD incorporation into RNAIII (Figure $2 \mathrm{C}$ and Figure $2 \mathrm{E}$ ). The unexpected revelation of the TSS of the P2 promoter being $G$ instead of $A$ (Figure 2E) provided us with an additional "NAD zero" control in our experiments, constituting a transcript that differed only in one nucleotide from the native one but was devoid of any 5'-NAD. This control further demonstrated that NAD captureSeq is not biased towards highly expressed RNAs unless they bear the NAD cap. Moreover, it also confirmed the reliability of the APBgelNorthern blot combination as a tool for analysing NAD-capped RNAs.

\subsection{NAD-RNAIII as a modulator of $S$. aureus physiology.}

For validating the function of RNAIII's NAD cap, it was essential that the RNAIII expression of the different $S$. aureus strains was not altered by the changes introduced in the promoter sequence. qPCR analysis confirmed the lack of bias in RNAlll content between $S$. aureus pCG-P3 and pCGP3(-1G) (Figure 3B). This experiment also showed lower RNAIII levels in the PCG-P2 strain (Figure $3 \mathrm{~B})$, which suggest that the P2 promoter is less active than the P3 promoter in these experiments. 
This finding is in agreement with the fact that in vitro, AgrA-mediated activation of transcription is more prominent at P3 than at P2 (Reynolds \& Wigneshweraraj, 2011). On the other hand, a recent in vivo study reported AgrA P affinity to P2 to be higher than to P3, previously assessed by Koenig et al. (2004), and this differential affinity being crucial for the agr positive feedback loop (Garcia-Betancur et al., 2017). According to transcriptome sequencing, the higher NAD modification ratio of RNAIII in S. aureus pCG-P3(-1G) (Figure 2C and Figure 2E) appears to downregulate the transcription of spa (protein A) and ssaA (staphylococcal secretory antigen SsaA) (Table S6). SsaA mRNA has been proposed (but not yet demonstrated) to base-pair with the 3'-end of RNAlll (Lioliou et al., 2016). spa mRNA is known to base-pair with RNAIII, in particular with helix 13 (Huntzinger et al., 2005), thereby blocking spa's Shine-Dalgarno sequence, leading to spa mRNA translation repression and degradation by endoribonuclease III (Bronesky et al., 2016). While within the primary sequence helix 13 is far away from the NAD-5'-end, in one of the proposed secondary structures of RNAIII, the $5^{\prime}$ and $3^{\prime}$-ends base-pair with each other (Novick et al., 1993), thereby localising the NAD in the vicinity of helix 13 . Hence, it is conceivable that the $5^{\prime}-N A D$ cap affects the folding of RNAIII and its interaction with the spa mRNA. A stronger interaction might lead to a decreased protein A production, which would ultimately favour the dissemination of S. aureus pCG-P3(-1G) isolates (Bronesky et al., 2016). Furthermore, four genes for a protease family occurring only in S. aureus, (Sp/A/B/C/D operon) (Reed et al., 2001) were upregulated in the strain with increased NADRNAIII. Also, the $S p /$ operon is induced by the agr-system with a mechanism that has not been elucidated but that might involve RNAIII (Reed et al., 2001). The Spl proteases have been implicated in tissue dissemination processes due to their ability to degrade host proteins (Paharik et al., 2016). Noteworthy, a recent study reported a decrease in the amount of HId in the spent medium obtained from an $S$. aureus $S p l$ deletion mutant, suggesting a positive correlation between RNAIII and Spl. On the other hand, the $\Delta S p /$ strain did not show alterations in Hla levels, proving that the agr system was not inhibited (Paharik et al., 2016). At this point, one could expect that the upregulation in Spl proteases in PCG-P3(-1G) together with the downregulation of protein $A$ and SsaA would generate a more invasive bacterium than pCG-P3. Nevertheless, evidence at protein level of these two targets would be necessary to predict more accurately the phenotypic effects. Transcriptome sequencing did not reveal significant changes in another major target of RNAIII, namely hla (Log2FC = -0.14). However, as RNAlll activates translation of $h$ la mRNA by base pairing between the 5'-UTRs of both RNAs (Morfeldt et al., 1995), an effect on the mRNA level of this gene was not expected.

On the protein level, the phenotypic effects were more notorious. Since pCG-P3(-1G) exhibits an upregulated Spl operon, an increase in Hld amount in supernatant could be expected. In contrast, a significant decrease of HId in cell culture filtrates of S. aureus PCG-P3(-1G) was observed (Figure 3C).

One explanation would be that the 5'-NAD cap in RNAlll might impair Hld translation. In eukaryotes, there are conflicting reports regarding the translatability of NAD-RNAs (Jiao et al., 2017; Wang et al., 2019), and there are no comparable data on prokaryotes which are not known to sense and require "cap" structures in translation. It has been suggested that the 3 '-end of RNAIII blocks HId translation by base-pairing with its Shine-Dalgarno (SD) sequence, making it inaccessible to ribosomes, thereby delaying the translation of Hld by $1 \mathrm{~h}$ after RNAIII transcription 
(Balaban \& Novick, 1995). Thus, the 5'-NAD cap might favour the interaction between the 5'-end and and some downstream sequences due to the pseudo-base-pairing of the nicotinamide moiety of the initiating NAD, which has been proposed to base-pair with C and T of DNA in the open promoter (Vvedenskaya et al., 2018). Hence, it appears plausible that the 5'-NAD cap of an RNA interacts similarly with $C$ and uridine $(U)$ residues inside the same molecule. Nevertheless, even if one assumes that NAD-RNA is not translated while ppp-RNA is, this could not explain how a $15 \%$ reduction in ppp-RNAIII in pCG-P3(-1G) compared to pCG-P3 (Figure 2C) can cause a 50\% decrease in translation product yield. We assume that this effect may be due to yet unknown factors that modulate $h / d$ translation. In the case of Hla, the changes observed in PCG-P3(-1G) compared to PCG-P3 are slightly lower than for HId (Figure 3C), which might imply a lower influence of the 5'-NAD-cap on the RNAllI-hla mRNA interaction than on RNAlll translation. Indeed, the fact that the $\mathrm{H} 2$ hairpin of RNAIII, which is the one predicted to interact with hla mRNA, is only nine nucleotides upstream of hld's SD sequence suggests that both might be similarly affected by the $5^{\prime}$-NAD cap. Like in the case of HId translation, nicotinamide's base-pairing flexibility might increase the probability of generating a 5'-end-3'-UTR duplex in RNAIII's secondary structure, sequestering both the SD sequence and $\mathrm{H} 2$ helix, and explaining the phenotypes obtained in S. aureus pCG-P3(-1G) (Figure $3 C$ and Figure 3D). Surprisingly, the in vitro analysis of RNAIII leader's secondary structure by SHAPE did not reveal differences related to the 5'-NAD cap (Figure 4A). In both RNAlll leader variants, the SD appeared to be accessible (Figure 4B). This structure would likely be compatible with translation of the embedded HId ORF regardless of the presence of the 5'-NAD cap. Of note, the analysis was done with a shortened version of RNAlll with the aim of detecting the presence of a mechanism that would block co-transcriptional translation. Furthermore, SHAPE measurements with full-length RNAIII revealed an accessible SD sequence as well (Figure 4B, Figure 4C, Figure 4D), an observation already reported in the chemical probing of RNAlll performed by Benito et al. (2000). Our data suggest that the lack of RNAlll's 3'-domain would not exert any effect on HId and Hla translation (Figure 4B, Figure S1G). In contrast, a mutant S. aureus strain with a truncated RNAIll devoid of its $3^{\prime}$-end domain (211 nt) showed an earlier Hld translation compared to the wild type strain (Balaban \& Novick, 1995). Likewise, deletions within 3'-end region of RNAIII also inhibit Hla expression (Novick et al., 1993). Thus, although the in vitro RNAIII SHAPE experiments do not explain the obtained phenotypes with decreased HId and Hla, in a regulated cellular co-transcriptional translation environment, the $5^{\prime}$-NAD cap could cause some differences and, induce different phenotypes.

While RNAIII has been studied intensively as a central regulator of bacterial physiology, a large number of different targets affected by it, and the diversity of mechanisms of action make it rather unlikely that only one stable secondary structure induces all these responses. Instead, inside the cell likely exists an equilibrium between different folds, each of them suited for specific purposes (Benito et al., 2000). The existence of such alternative folds has been hinted at by the inaccessibility of a fraction of in vitro-transcribed NAD-RNAlll to NudC cleavage, and its modulation by an unfolding / folding cycle (Figure 3A). Thus, the existence in the cell of an RNAlll subpopulation that is sensitive to its $5^{\prime}$-modification state and is responsible for both $h / d$ and $h / a$

411 The fact that the RNAlll sequence is highly conserved among $S$. aureus strains led us to 412 hypothesize that the incorporation of NAD into RNAlll should be strictly regulated and therefore 
413 the evolution selected the $-1 \mathrm{~T}$ at P3 promoter. In such a way, S. aureus may ensure the right 414 (intermediate) level of NAD incorporation into RNAIll and preserves its optimal ensemble of 415 secondary structures. Assuming this, the 5'-NAD cap might serve as modulator of RNAIII's 416 secondary structure. Moreover, the NADylation of RNAIll is likely dependent on the bacterial 417 redox state and might be a new mechanism to fine-tune agr activity.

\subsection{Outlook.}

419 In this study, we have discovered another prokaryotic organism that possesses NAD-capped 420 RNAs. However, it constitutes the first evidence of this phenomenon in pathogenic bacteria to 421 date. More importantly, we have found that a crucial regulatory and protein-coding RNA (RNAIII) 422 is strongly NAD-modified and that alterations on its NAD-modification state lead to significant 423 effects that modulate $S$. aureus's cytotoxicity that could be related to an alternative secondary 424 structure of RNAIII. However, and despite these exciting findings, the role of 5'-NAD-RNAIII 425 remains unclear. Further studies will be conducted to unravel how exactly the NAD cap changes 426 RNAIII's secondary structure and how this change contributes to the overall secondary structure 427 ensemble of RNAIII. Furthermore, in vivo studies applying our mutant S. aureus strains to animal 428 infection models are planned to study the pathogenicity of this bacterium.

\section{$4296 \quad$ Materials and Methods}

\section{$430 \quad 6.1 \quad$ Bacterial strains.}

431 S. aureus ATCC 25923 was the selected strain to detect the presence of NAD covalently linked to 432 RNA by UPLC-MS analysis, NAD captureSeq, and pull-down of specific RNAs. S. aureus HG001 was 433 used as wild-type and for the mutational studies. The pCG-246-based (Helle et al., 2011) shuttle 434 plasmids pCG-P3, pCG-P2 and pCG-P3(-1G) were first grown in E. coli K-12 strain, then 435 transformed into the restriction-deficient $S$. aureus RN4220, and finally electroporated into $S$. 436 aureus HG001 $\triangle R N A I I I$ as described before (Charpentier et al., 2004). For the cytotoxicity assay, 437 the constructs were introduced into $S$. aureus $\triangle R N A I I I \Delta p s m \alpha B$. Genomic DNA from $S$. aureus 438 ATCC 25923 was used to amplify the P3 promoter, P2 promoter, and RNAIll sequences (Q5 Hot 439 Start High-Fidelity DNA Polymerase, NEB). The bacterial strains used in this study are summarised 440 in Table S9.

\subsection{Generation of constructs.}

442 The RNAlll sequence with the native P3 promoter sequence upstream was amplified from 443 Genomic DNA from S. aureus ATCC 25923. The PCR amplification was carried out with the primers 444 Fwd-P3-RNAIII/Rv-P3-RNAIII; as a consequence, the restriction sites BamHI and EcoRI were 445 introduced in the amplicon. The P2 promoter sequence was fused to RNAlll by the following 446 procedure: a PCR with the primers Fwd-P2/Rv-P2hyb was performed in order to generate a P2447 amplicon with a 20 bp overhang on its 3'-end which was complementary to RNAlll's first 20 nt. 448 The PCR with primers Fwd-RNAIII/Rv-RNAIII originated a second amplicon containing the whole 449 RNAIII sequence. Both amplicons were used as primers and subjected to PCR in order to generate 450 the P2-RNAlll product, which contained BamHI and EcoRI restriction sites. Both PCR products 
were treated with BamHI and EcoRI and cloned into the pCG-246 shuttle vector (Helle et al., 2011) yielding the constructs pCG-671 and pCG-672. The RNAIII terminator sequence was introduced afterwards in both of the constructs by site-directed mutagenesis generating pCG-P3 and pCG$\mathrm{P} 2$ plasmids. Besides, a mutation at the -1 position $(-1 \mathrm{~T}$ to $-1 \mathrm{G})$ respect to the TSS of the $\mathrm{P} 3$ promoter was inserted by site-directed mutagenesis, yielding plasmid pCG-P3(-1G). All primers used are summarised in Table S3.

\subsection{NAD captureSeq and RNA-seq Next Generation Sequencing (NGS).}

In order to identify those NAD-RNAs from $S$. aureus, we have made use of NAD captureSeq as described previously (Winz et al., 2017) and applied to $100 \mu \mathrm{g}$ total RNA from S. aureus ATCC 25923 per sample isolated at the late-exponential phase $\left(O D_{600}=1.5\right)$. A NAD captureSeq variant was also used in order to compare the enrichment of specific RNAs between $S$. aureus strains (pCG-P2, pCG-P3, and pCG-P3(-1G)). For that, $15 \mathrm{fmol}$ of variable length $(61,104,205,302,400$ nt) NAD-RNAs were spiked into each sample, acting as internal standards (IS). The PCR products were purified by polyacrylamide (PA) gel electrophoresis (PAGE), and the range between 150 and $300 \mathrm{bp}$ selected (Figure S1A). This size selection helped to remove the primer dimers as well. Afterwards, the quality of the samples was analysed by Bioanalyzer measurements (Bioanalyzer 2100, Agilent Technologies, Santa Clara, California) using the Agilent DNA 1000 Kit (Agilent). The libraries were multiplexed and submitted to NGS on a NextSeq500 sequencer (Illumina, San Diego, California) with the following parameters: single-end reads, 75-bp read length, read depth 400 million. Besides, $20 \%$ of PhiX control DNA was spiked into the samples to provide sufficient read complexity. The NGS data analysis was done using an in-house pipeline. Briefly, after obtaining the raw reads, the leading guanosines were trimmed, and the 3' adapter was removed by clipping. Once processed, the reads were mapped to the reference genome Staphylococcus aureus subsp. aureus NCTC 8325 (European Nucleotide Archive, Assembly: GCA_000013425.1) and to the IS RNA sequences (in the case of the quantitative NAD captureSeq, Table S4). The software used for mapping was Burrows-Wheeler Aligner (BWA-MEM, version: 0.7.13) (H. Li, 2013). To identify the gene hits, HTSeq (version: 0.6.0) (Anders, Pyl, \& Huber, 2015) was used. Also, DESeq (Anders \& Huber, 2010) was used for statistical analysis. Finally, the obtained hits were checked and visualised with the Integrated Genome Browser (Nicol et al., 2009). RNA-seq analysis was conducted with total RNA of $S$. aureus pCG-P2, pCG-P3, and pCG-P3(-1G) strains (biological triplicates, $5 \mu \mathrm{g}$ total RNA each sample) isolated at the late-exponential phase $\left(\mathrm{OD}_{600}\right.$ = 2.5). For removal of ribosomal RNA from samples, the Ribo-Zero rRNA Removal Kit (GramPositive Bacteria, Illumina) was used. The libraries were prepared with NEBNext Ultra II Directional RNA LibraryPrep Kit for Illumina (New England Biolabs (NEB), Ipswitch, Massachussets) together with the NEBNext Multiplex Oligos for Illumina (NEB). The removal of primer excess and primer dimers was done by the Agencourt AMPure XP RNA Clean beads (Beckman Coulter, Brea, California). The amount of sample was assessed by Qubit HS DNA assay (Thermo Fisher Scientific, Waltham, Massachussets), whereas the sample quality was checked with Agilent Tape Station D1000 for DNA. Samples were equimolarly pooled before 50 SE sequencing on the Illumina HiSeq platform. NGS data analysis was performed with an in-house pipeline, and the reads were mapped to the reference genome Staphylococcus aureus subsp. aureus NCTC 8325 (European Nucleotide Archive, Assembly: GCA_000013425.1). 


\subsection{Total RNA isolation.}

494 S. aureus strains were grown at $37^{\circ} \mathrm{C}$ with shaking at $200 \mathrm{rpm}$ in LB broth (Lennox), and cells 495 were harvested at $\mathrm{OD}_{600}=2.5$ (experiments conducted with $S$. aureus $\mathrm{HGO01}$ plasmid496 transformed strains) and $\mathrm{OD}_{600}=1.5$ (experiments conducted with S. aureus ATCC 25923). The 497 RNA was extracted using TRIzol reagent (Thermo Fisher Scientific). Briefly, the pelleted cells were 498 resuspended in TE buffer ( $30 \mathrm{mM}$ Tris- $\mathrm{HCl}, 1 \mathrm{mM}$ EDTA, $\mathrm{pH}=8.0$ ) supplemented with lysozyme $20 \mathrm{mg} / \mathrm{mL}$ (Sigma-Aldrich, Saint Louis, Missouri) and $80 \mu \mathrm{g} / \mathrm{mL}$ lysostaphin (Sigma-Aldrich) and incubated $30 \mathrm{~min}$ at $37{ }^{\circ} \mathrm{C}$. The cells were incubated for $30 \mathrm{~min}$ at $-80{ }^{\circ} \mathrm{C}$ before the addition of the TRIzol reagent. Afterwards, the protocol proceeded according to the manufacturer's instructions. Samples were treated with DNase I (1.5 U/mg total RNA, Roche, Basel, Switzerland) at $37^{\circ} \mathrm{C}$ for 1 hour to remove the genomic DNA, then they were P/C/I-chloroform-extracted and precipitated. The RNA was washed twice with $80 \%$ ethanol and dissolved in Millipore water. The quality of the RNA was assessed by agarose gel electrophoresis (Figure $\mathrm{S} 1 \mathrm{H}$ ). The concentration and purity of the total RNA were measured by Nanodrop (Thermo Fisher Scientific), paying attention to $\mathrm{OD}_{260} / \mathrm{OD}_{280}$ and $\mathrm{OD}_{260} / \mathrm{OD}_{230}$ ratios.

\subsection{Quantitative PCR.}

To confirm the enrichment of the obtained hits at the cDNA level and thereby rule out the possible PCR bias, qPCR measurements were carried out as described before (Cahová et al., 2015). $20 \mu \mathrm{L}$ reactions were performed in triplicate using $3 \mu \mathrm{L}$ cDNA (1:50 diluted) as a template. When confirming the cDNA enrichment of the hits, APDRC-treated sample cDNA with cDNA of the minus ADPRC control were compared by the $2^{-\Delta \Delta C}$-method (Livak \& Schmittgen, 2001). The 5SrRNA gene was used as internal control and Millipore water as a negative control. Another qPCR assay was performed to check the hld/RNAlll levels of the different $S$. aureus strains (pCGP2, pCG-P3, and pCG-P3(-1G)). $5 \mu$ g of total RNA (harvested at late-exponential phase, biological triplicates) from each strain was reverse transcribed with Superscript IV reverse transcriptase (Thermo Fisher Scientific) following the manufacturer's instructions. $3 \mu \mathrm{L}$ cDNA (1:100 diluted) per $20 \mu \mathrm{L}$ reaction were used as the template. The gyrB gene was used as internal standard and Millipore water as a negative control. Standard curves were determined for each gene, using purified chromosomal DNA at concentrations of 0.005 to $50 \mathrm{ng} / \mathrm{ml}$. All qPCR experiments were performed in a Light Cycler 480 instrument (Roche) using the Brilliant III Ultra-Fast SYBRGreen qPCR Mastermix (Agilent Technologies). The data were analyzed with the Light Cycler 480 Software (Agilent Technologies). The primers used for qPCR analysis are listed in Table S3.

\subsection{Detection of HId by HPLC/ESI-MS.}

526 The detection of HId levels from different S. aureus strains was performed by high-performance 527 liquid chromatography/electrospray ionisation mass spectrometry (HPLC/ESI-MS) of overnight 528 culture filtrates as described earlier (Queck et al., 2008) with minor changes. The column (Zorbax 529 SBC8, $2.1 \times 50 \mathrm{~mm}, 3.5 \mu$, Agilent Technologies) was run at $0.3 \mathrm{ml} / \mathrm{min}$ with a gradient of $0.1 \%$ 530 trifluoroacetic acid in water to $0.1 \%$ trifluoroacetic acid in acetonitrile. HPLC-MS experiments 531 were performed on a Bruker microTOFQ-II ESI mass spectrometer (Bruker, Billerica, 532 Massachussets) connected to an Agilent 1200 Series HPLC system equipped with a multi- 
533 wavelength detector (Agilent Technologies). ESI was used with a capillary voltage of 4,500 V, and 534 the collision voltage was set to $10 \mathrm{eV}$. The drying gas temperature was $200^{\circ} \mathrm{C}$, the drying gas flow 535 rate was $6 \mathrm{Lmin}^{-1}$, and the detector was operated in positive ion mode. Mass spectra were 536 recorded on a range from $250 \mathrm{~m} / \mathrm{z}$ to $3,000 \mathrm{~m} / \mathrm{z}$. The two $\mathrm{m} / \mathrm{z}$ peaks in the mass spectrum for HId 537 (formylated and deformylated version, Figure S1F) were used to calculate PSM concentration by 538 integration using ACD/Spectrus software (Advanced Chemistry Development (ACD), Toronto, 539 Canada).

\section{$540 \quad 6.7$ Western blotting of Hla.}

541 One milliliter of cell culture filtrates from each strain (harvested at $O_{600}=2.5$ ) was filtrated and concentrated (final volume $20 \mu \mathrm{L}$ ) through ultracentrifugal filters (30 kDa MWCO, Amicon, Merck, Darmstadt, Germany) and analysed by $10 \%$ SDS-PAGE. After the run, SDS-PA gels were blotted onto Amersham Hybond P $0.2 \mu \mathrm{m}$ PVDF membranes (GE Healthcare, Chicago, Illinois) using an EasyPhor Semi-Dry-Blotter (Biozym Scientific, Hessisch Oldendorf, Germany). Membranes were blocked in TBST (Tris-buffered saline with 0.1\% Tween 20) supplemented with $5 \%$ milk powder (Carl Roth, Karlsruhe, Germany). Afterwards, membranes were incubated with antistaphylococcal alpha-toxin rabbit antibody (1:5000, Sigma-Aldrich) in washing buffer (TBST with 1\% milk powder). After washing, Alexa Fluor Plus 488-conjugated goat anti-rabbit IgG (Thermo Fisher Scientific) in washing buffer (1:10000) was applied over the membranes. Membranes were washed with $50 \mathrm{mM}$ Tris- $\mathrm{HCl}, \mathrm{pH} 7.25$, and subsequently scanned using a Typhoon FLA 9500 imager (GE Healthcare). Quantification was done with ImageQuant TL software (GE Healthcare).

\subsection{Detection of NAD covalently bound to RNA by UPLC/MS.}

Samples (total RNA and pull-down RNA) were prepared as described before (Frindert et al., 2018). Briefly, RNA was extensively washed with decreasing urea concentrations in ultracentrifugal filters (10 kDa MWCO, Amicon, Merck). RNA was recovered and subjected to NudC and alkaline phosphatase (Sigma-Aldrich) treatment $\left(1 \mathrm{~h}\right.$ at $37^{\circ} \mathrm{C}, 2 \mathrm{~h}$ for pull-down RNA) in the presence of the MS internal standard (d4-riboside nicotinamide, Toronto Research Chemicals, Ontario, Canada). Afterwards, the reaction mixtures were filtered through $10 \mathrm{kDa}$ ultracentrifugal filters (Merck) and dried under reduced pressure. Then, samples were analysed by UPLC-MS following the previously described protocol (Frindert et al., 2018). A calibration curve was recorded for $r$ NA for each analytical batch. $\mathrm{M} / \mathrm{z}$ peaks of the mass spectra from the analyte and internal standard were integrated with TargetLynx software (Waters corporation, Milford, Massachussets). The amount of injected r-NA was calculated by integration of the corresponding $\mathrm{m} / \mathrm{z}$ peak using the TargetLynx software and the calibration curve.

\subsection{Gel electrophoresis and Northern Blot analysis.}

567 RNA was separated by denaturing PAGE. For NAD captureSeq NGS library generation (Qualitative

568 and Quantitative), the cDNA amplification products were purified by native PAGE. APBgels (Nübel 569 et al., 2017) were used to separate and purify NAD-RNA and ppp/p-RNA. Northern blot analysis 570 was performed as described before (Cahová et al., 2015). RNA was separated either by PAGE or 571 PAGE-APBgels (200 V, $90 \mathrm{~min}$ ), blotted onto a Whatman Nytran SuPerCharge nylon blotting 
membrane (Merck) for $3 \mathrm{~h}$ ( $4 \mathrm{~h}$ for APBgels at $4{ }^{\circ} \mathrm{C}$ to avoid buffer evaporation) at $250 \mathrm{~mA}$ using an EasyPhor Semi-Dry-Blotter (Biozym Scientific), and UV-crosslinked. Membranes were prehybridized in Roti-Hybri-QuickBuffer (Carl Roth) for $2 \mathrm{~h}$ at $48^{\circ} \mathrm{C}$. Afterward, $5 \mu \mathrm{L}$ RNA radiolabeled probe (Table S3) was added and incubated overnight at $48{ }^{\circ} \mathrm{C}$ in a hybridization oven with rotation. The templates for the probes were prepared by PCR using Taq DNA polymerase (prepared laboratory stock). Probes were prepared by in vitro transcription (IVT) in the presence of $35 \mu \mathrm{Ci} \alpha-{ }^{32} \mathrm{P}-\mathrm{ATP}$ and $35 \mu \mathrm{Ci} \alpha{ }^{32} \mathrm{P}-\mathrm{CTP}(3,000 \mathrm{Ci} / \mathrm{mmol}$, each, Hartmann Analytic, Braunschweig, Germany). The IVT reactions were treated with DNase I (Roche), P/C/Ichloroform-extracted, ethanol-precipitated and dissolved in $30 \mu \mathrm{L}$ Millipore water. The blot was washed for 30 min with wash solution 1 ( $2 x$ SSC, $0.1 \%$ SDS), 30 min with wash solution 2 (1x SSC, $0.1 \%$ SDS) for $30 \mathrm{~min}$ with wash solution 3 ( $0.25 \times$ SSC, $0.1 \%$ SDS). Radioactive RNA was visualized using storage phosphor screens (GE Healthcare) and a Typhoon FLA 9500 imager (GE Healthcare).

\subsection{Preparation of NAD-RNAIII and ppp-RNAIII markers and IS NAD-RNAs.}

The RNAIII markers used in the Northern blot analysis were prepared by IVT. The IVTs were performed as described earlier (Huang, 2003). Each $100 \mu$ IVT reaction contained: 1.5-2 $\mu \mathrm{g}$ DNA template and $4 \mathrm{mM}$ of each NTP $(6 \mathrm{mM}$ NAD for NAD-RNAs; ATP concentration was reduced to $2 \mathrm{mM}$, or without NAD for ppp-RNAs). The reactions were performed in transcription buffer (40 $\mathrm{mM}$ Tris- $\mathrm{HCl} \mathrm{pH}=8.1,1 \mathrm{mM}$ spermidine, $22 \mathrm{mM} \mathrm{MgCl}_{2}, 0.01 \%$ Triton X-100, $10 \mathrm{mM}$ dithiothreitol (DTT), 5\% DMSO). Reactions were stopped upon addition of denaturing gel loading buffer (10\% TBE in formamide containing $0.05 \%$ bromophenol blue, $0.5 \%$ xylene cyanol blue) and purified by PAGE with standard running conditions (1x TBE buffer, $600 \mathrm{~V}$ ). RNAs were excised after the run, eluted overnight in $0.3 \mathrm{M}$ sodium acetate $(\mathrm{pH}=5.5)$ at $19{ }^{\circ} \mathrm{C}$, isopropanol-precipitated and dissolved in Millipore water. DNA templates for the RNAll markers were prepared by PCR amplification of genomic DNA from S. aureus ATCC 25923 using Q5 Hot Start High-Fidelity DNA Polymerase (NEB) and the primers listed on Table S3. The PCR products were purified with the QIAquick PCR purification kit (Qiagen, Hilden, Germany) before the IVT reactions.

The 5 different IS NAD-RNAs used for NAD captureSeq were also prepared by IVT (Huang, 2003). As a template, regions of $E$. coli's K12 genome with no homology within $S$. aureus genome were PCR amplified (Q5 Hot Start High-Fidelity DNA Polymerase (NEB)) with the primers summarised in Table S3. The PCR products were purified with QIAquick PCR purification kit (Qiagen) before IVT. IVT reactions were PAGE purified, as described above. Afterwards, the RNAs were additionally purified on APBgels (5\% PA, 0.4\% APB) (Nübel et al., 2017), loaded with APBgels loading buffer ( $8 \mathrm{M}$ urea, $10 \mathrm{mM}$ Tris- $\mathrm{HCl} \mathrm{pH}=8.0,50 \mathrm{mM}$ EDTA, xylene cyanol and bromophenol) and run in 1X TAE (550 V). The sequences of each IS NAD-RNA are summarised in Table S4.

\subsection{Preparation of radiolabeled pure NAD-RNAIII and NudC cleavage assay.}

The radiolabeled (body labelled) pure NAD-RNAIII was prepared by IVT essentially as described before (Huang, 2003) but with the presence of $100 \mu \mathrm{Ci} \alpha$-32 P-UTP $(3,000 \mathrm{Ci} / \mathrm{mmol}$, Hartmann Analytic) per $100 \mu \mathrm{L}$ reaction. The IVT reaction was first PAGE-purified and afterwards purified on APB gels as described above to obtain $100 \%$ NAD-modified RNAllI, which was subjected to NudC cleavage. The NudC cleavage assay was carried out as described before (Cahová et al., 2015) but with a ratio of 2 NudC:1 RNAlll. $10 \mu \mathrm{L}$ reactions per triplicate in $1 x$ degradation buffer 
$613(25 \mathrm{mM}$ Tris- $\mathrm{HCl} \mathrm{pH}=7.5,50 \mathrm{mM} \mathrm{NaCl}, 50 \mathrm{mM} \mathrm{KCl}, 10 \mathrm{mM} \mathrm{MgCl}, 10 \mathrm{mM}$ DTT) were incubated 614 for $5,10,20,30,60$ and $120 \mathrm{~min}$ at $37^{\circ} \mathrm{C}$. Reactions were stopped by addition of APBgel loading 615 buffer and analysed on APBgels (6\% PA, $0.7 \%$ APB). The stability of NAD-RNAIII in 1x degradation 616 buffer was assessed by incubating it for 2 hours at $37{ }^{\circ} \mathrm{C}$ in the absence and the presence of the 617 enzyme (Figure 1, Figure 3A).

618 Additional reactions per triplicate were performed to test the influence of RNAIII's secondary 619 structure on NudC cleavage capacity. After a 60 incubation at $37{ }^{\circ} \mathrm{C}$ in the presence of NudC, 620 samples were heated up to $75^{\circ} \mathrm{C}$ for $2 \mathrm{~min}$ and cooled down to $25^{\circ} \mathrm{C}$ (NAD-RNAlll folding after 621 digestion). Afterward, fresh NudC was added, and samples underwent a second round of 622 incubation (60 $\min$ at $37^{\circ} \mathrm{C}$, Figure 1, Figure $3 \mathrm{~A}$ ).

623 Radioactive RNA was visualised using storage phosphor screens (GE Healthcare) and a Typhoon 624 FLA 9500 imager (GE Healthcare).

\section{$625 \quad 6.12$ Pull-down of RNAIII and 5SrRNA.}

626 RNAs were specifically isolated out of $300 \mu \mathrm{g}$ total RNA as described previously (Cahová et al., 627 2015; Frindert et al., 2018). Briefly, $150 \mu \mathrm{L}$ Streptavidin Sepharose High Performance beads (GE 628 Healthcare) were loaded onto Mobicol Classic columns (MoBiTec, Göttingen, Germany), washed 629 with 1x PBS and supplemented with biotinylated DNA probes (Biomers, Ulm, Germany, Table S3) 630 dissolved in $1 \times$ PBS ( $75 \mu \mathrm{L}, 25 \mathrm{mM}$, with incubation for $10 \mathrm{~min}$ at 25 ㅇ $\mathrm{C}$ with shaking at $1000 \mathrm{rpm})$. 631 After washing and equilibration of the beads (with 1x PBS and pull-down buffer (10 mM Tris- $\mathrm{HCl}$

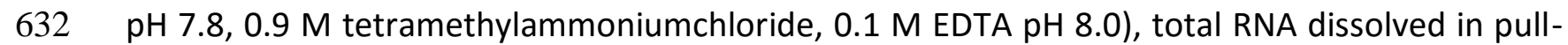
633 down buffer was added. RNA was then incubated for $10 \mathrm{~min}$ at $65^{\circ} \mathrm{C}$ and then for $25 \mathrm{~min}$ at room 634 temperature with rotation (Tube Rotator, VWR, Radnor, Pennsylvania). Beads were washed with 635 Millipore water, and RNA was eluted upon addition of $2 \mathrm{mM}$ EDTA (pre-heated to $75{ }^{\circ} \mathrm{C}$ ). The 636 eluted RNA was precipitated with $0.5 \mathrm{M}$ ammonium acetate and isopropanol in a reaction tube 637 and dissolved in Millipore water. Northern blot analysis with the pull-down eluates and probes 638 vs RNAlll and 5SrRNA was performed (Figure S1I). Afterwards, RNA was further purified by $8 \%$ 639 PAGE and the bands corresponding to RNAlll and 5SrRNA excised (Figure S1J). After RNA 640 precipitation and washing, RNA concentration was measured with Qubit RNA BR Assay Kit 641 (Thermo Fisher Scientific). The purified RNA was used for: Northern bot analysis (Figure S1K) and 642 NudC treatment with subsequent UPLC-MS analysis as described above. For DNAzyme treatment, 643 the precipitated RNA was used without further PAGE purification (Figure 1E).

\section{$644 \quad 6.13$ Generation of RNA-cleaving DNA enzymes.}

645 Four different RNA-cleaving DNAzymes were generated following the instructions by Joyce 646 (Joyce, 2001) to generate a shorter RNAllI. DNAzymes were tested on RNAIII in vitro, and the 647 most efficient one was selected for further experiments (DNAzyme II, Figure S1L). The cleavage 648 of RNAlll by DNAzyme II (37 nt, Table S3) generated a 125 nt product containing RNAllI's 5'649 terminus. For the in vitro cleavage assays, $10 \mu \mathrm{L}$ reactions were set up in 1x DNAzyme buffer (10 $650 \mathrm{mM}$ Tris- $\mathrm{HCl} \mathrm{pH}=8.0,5 \mathrm{mM} \mathrm{NaCl}$ ) supplemented with $1 \mu \mathrm{M} \mathrm{NAD/ppp-RNAIII,} 0.2 \mathrm{mM}$ DTT, 25 $651 \mathrm{mM} \mathrm{MgCl}_{2}$, and $1 \mu \mathrm{M}$ DNAzyme II. First, RNAlll was folded in the presence of $0.2 \mathrm{mM}$ DTT by 652 incubation for $2 \mathrm{~min}$ at $75{ }^{\circ} \mathrm{C}$, followed by a cool down to $25^{\circ} \mathrm{C}$. Afterwards, the remaining 653 reagents were added $\left(\mathrm{MgCl}_{2}\right.$, DNAzyme II) and reactions were incubated $1 \mathrm{~h}$ at $37^{\circ} \mathrm{C}$. Reactions 
654 were stopped by addition of denaturing gel loading buffer and analysed by classical PAGE and 655 APBgels followed by Northern blot as described above (Figure S1L). The same procedure was 656 followed with RNAlll obtained after pull-down (biological triplicates, $2 \mu \mathrm{M}$ DNAzyme II) but 657 including an additional NudC treatment $\left(1.5 \mu \mathrm{M} \mathrm{NudC}, 1 \mathrm{~h} 37^{\circ} \mathrm{C}\right)$ right after RNA cleavage as a 658 negative control (to deplete NAD-RNAIII). NAD-RNAIII and ppp-RNAIII treated with DNAzyme II 659 and I were used as reference markers in the Northern Blot assay of RNAlll pull down samples.

6606.14 Analysis of 5'-ends by circular RT-PCR and Sanger sequencing.

661 To analyse RNAIII's TSS on the different S. aureus mutant strains (pCG-P3, pCG-P2, pCG-P3(-1G)), 662 circular RT-PCR was carried out as described before (Slomovic \& Schuster, 2013) with small 663 differences. In essence, $10 \mu \mathrm{g}$ of total RNA of each strain was treated with RNA 5'664 Polyphosphatase (Epicentre, Madison, Wisconsin). The dephosphorylated RNAs were self-ligated 665 by T4 RNA ligase (Thermo Fisher Scientific) treatment, and the predicted 3'-end-5'-end ligated 666 region of RNAIII was amplified by nested PCR with the primers listed in Table S3. The purified 667 amplicons were then phosphorylated by T4-Polynucleotide Kinase (Thermo Fisher Scientific) 668 treatment before cloning them into the plasmid pDisplay-AP-CFP-TM (Addgene plasmid \#20861 669 (pDisplay-AP-CFP-TM was a gift from Alice Ting (Howarth, Takao, Hayashi, \& Ting, 2005)), 670 previously digested with EcoRV (NEB) and dephosphorylated by alkaline phosphatase (Thermo 671 Fisher Scientific)). The blunt-end ligation was carried out by T4-DNA ligase (Thermo Fisher 672 Scientific). The ligation mixture was transformed into $E$. coli $\mathrm{DH} 5_{\alpha}$ competent cells. The 673 transformed cells were streaked on Petri dishes containing LB-agar supplemented with ampicillin $674\left(100 \mu \mathrm{g} / \mathrm{mL}\right.$, Carl Roth) and incubated overnight at $37^{\circ} \mathrm{C}$. Single colonies were picked, the 675 plasmids isolated and subjected to high throughput Sanger sequencing (Microsynth SeqLab, 676 Göttingen, Germany). All the enzymatic treatments were performed according to the 677 manufacturer's instructions.

\subsection{Cytotoxicity assay.}

679 Overnight cultures were sub-cultured to $\mathrm{OD}_{600}=0.05$ in LB-broth (Lennox) and then grown for $68022 \mathrm{~h}$. Bacterial supernatants were harvested and filtered through a $0.45 \mu \mathrm{m}$ filter (Merck) and 681 analysed for its cytotoxic potential. The cytotoxicity assay was performed essentially as described 682 (Munzenmayer et al., 2016) with the exception that $1 \times 10^{5}$ THP1 cells were seeded in 96-well cell 683 8culture plates in a final volume of $100 \mu \mathrm{L}$. Differentiated THP1 macrophages were treated with $684200 \mu \mathrm{L}$ of each bacterial supernatant. THP1 cells with culture medium were used as negative control and THP1 cells treated with Phosphate Buffered Saline (PBS) containing 1\% TritonX-100 686 were used as a positive control. The cytotoxic potential of the samples was determined from 687 THP1-cell supernatants after 3 hours by using the Cytotoxicity Detection Kit (Roche) according to 688 the manufacturer's instructions.

\section{$689 \quad 6.16$ Structural analysis of RNAIIl variants by SHAPE}

$6901 \mathrm{M} 7$ was synthesized as described (Mortimer \& Weeks, 2007). A shorter version of RNAlll 691 comprising nucleotides 1 to 113 (RNAlll leader) and full-length RNAlll with different 5'-ends (5'692 NAD cap or triphosphate) were prepared by in vitro transcription as described above. In the case 
693 of full-length RNAIII, a mixture containing 1:1 NAD-RNAIll and ppp-RNAIII was prepared 694 whereas the obtained NAD-RNAIII leader was $100 \%$ NAD-modified. The IVT template was generated by PCR with the primers RNAIII-leader-FW and RNAIII-leader-RV. Genomic DNA from S. aureus ATCC 25923 was used for the PCR. The NAD-supplemented IVT reaction was doublepurified, first by denaturing PAGE and afterwards by APBgels, yielding NAD-RNAIII leader and ppp-RNAIII leader (Figure S1M). SHAPE was performed as described with minor modifications (Wilkinson et al., 2006). Briefly, 8 pmol of RNA dissolved in $47.8 \mu \mathrm{L}$ Millipore water were incubated for $2 \mathrm{~min}$ at $75^{\circ} \mathrm{C}$ and then cooled down to $60{ }^{\circ} \mathrm{C}$ with a ramp of $0.1{ }^{\circ} \mathrm{C} / \mathrm{s}$. Afterwards, $24.2 \mu \mathrm{L}$ of Dulbecco's Phosphate Buffered Saline (DPBS, Sigma-Aldrich) supplemented with $3 \mathrm{mM} \mathrm{MgCl} 2$ were added to the samples, and they were incubated $2 \mathrm{~min}$ at $60^{\circ} \mathrm{C}$. Samples were then cooled down to $30{ }^{\circ} \mathrm{C}(0.1$ ${ }^{\circ} \mathrm{C} / \mathrm{s}$ ) and kept $2 \mathrm{~min}$ at this temperature. During this step, each sample was equally divided into two vials (sample vial and control vial). The vials were heated up to $37^{\circ} \mathrm{C}$, and then $4 \mu \mathrm{L}$ of 100 $\mathrm{mM} 1 \mathrm{M} 7$ (10 mM final concentration) was added to sample vial. $1 \mathrm{M} 7$ was dissolved in dry DMSO (Sigma-Aldrich), so the reaction control was supplemented with the same volume of dry DMSO as in the sample $(4 \mu \mathrm{L})$. The reaction mixtures were incubated for $20 \mathrm{~min}$ at $37^{\circ} \mathrm{C}$. Finally, reactions were stopped by adding 1 reaction volume of Millipore water, and the RNA was precipitated by ethanol in the presence of $0.3 \mathrm{M}$ sodium acetate. The precipitated RNA was washed twice with $80 \%$ ethanol and dissolved in Millipore water to a concentration of 0.5 $\mathrm{pmol} / \mathrm{mL}$. 5 '-end with $3 \mu \mathrm{L}$ of $\mathrm{y}^{-32} \mathrm{P}$-ATP $(3,000 \mathrm{Ci} / \mathrm{mmol}$, Hartmann Analytic) per $20 \mu \mathrm{L}$ reaction by using T4 polynucleotide kinase (Thermo Fisher Scientific), and further purified with the QIAquick Nucleotide Removal Kit (Qiagen). Both steps were performed following the manufacturer's instructions. The primer extension assay was applied to the RNA samples by using Superscript IV reverse transcriptase (Thermo Fisher Scientific). The reaction volume was set to $10 \mu \mathrm{L} .1 \mathrm{pmol}$ of treated RNA per reaction was used as a template for the reaction together with $5 \mu \mathrm{L}$ of 5 '-end radiolabeled DNA primer $1 \mu \mathrm{M}$. A sequencing ladder was generated by reverse transcription of 1 pmol non-treated in vitro-transcribed ppp-RNAlll leader supplemented with $0.5 \mathrm{mM}$ deoxynucleotide triphosphate mix each (Sigma-Aldrich), and $1 \mathrm{mM}$ of the corresponding dideoxynucleotide triphosphate (Jena Bioscience, Jena, Germany). Reactions were performed according to the manufacturer's instructions. The removal of residual RNA was done by addition of $2 \mu \mathrm{L} 1 \mathrm{M} \mathrm{NaOH}$ to the samples followed by a 5 min incubation at $90{ }^{\circ} \mathrm{C}$. Samples were then neutralised by the addition of $2 \mu \mathrm{L} 1 \mathrm{M} \mathrm{HCL}$ and stored at $-20^{\circ} \mathrm{C}$ in denaturing gel loading buffer before being analysed by PAGE.

729 Samples processed in triplicate were analysed by $15 \%$ PA sequencing gels with standard running

730 conditions (TBE buffer, $2000 \mathrm{~V}$, $4 \mathrm{~h} 30 \mathrm{~min}$ run time, Figure S1L). Radioactive cDNA was visualised with storage phosphor screens (GE Healthcare) and a Typhoon FLA 9500 imager (GE Healthcare). Quantification of PA sequencing gels was done with the software SAFA (Laederach et al., 2008). The intensities of the bands were normalised, and the control lanes (DMSO treated) were subtracted from the sample lanes (1M7 treated) to obtain the SHAPE values for each nucleotide. The SHAPE values for each nucleotide were afterwards used in the RNAstructure software (Reuter \& Mathews, 2010) to create a structure prediction for the RNA sequence. 


\subsection{Statistical analysis}

Except for NGS data analysis, where DESeq statistics was used (Anders \& Huber, 2010), all statistics were analysed using the software Prism 6 version 6.01 (GraphPad, San Diego, California). Error bars depict standard deviations in all experiments. For specific data sets, identification of outliers was performed by Grubbs' method (Alpha $=0.2$ ). When comparing two groups, the parametric unpaired two-tailed Student's t-test was selected. For the analysis of experiments involving three or more groups, the parametric one-way ANOVA test was done. The applied Post hoc analysis was Tukey's multiple comparisons-test. Differences were considered significant when $P<0.05$.

\section{$7 \quad$ Author contributions}

H.M. and A.J. designed the study. H.M., N.K., Y.Z., and G.N. performed the experiments. H.M., Y.Z., G.N., S.E.G., C.W., and A.J. analyzed the data. H.M. and A.J. wrote the initial draft of the manuscript, and H.M., A.J., C.W and S.E.G. edited the manuscript.

\section{Acknowledgements}

This work was financed by Baden-Württemberg Stiftung (grant BWST_NCRNA_045). We thank all the members of the Jäschke Group for their support and input during the discussions, A. Dalpke and K. Kubatzky for the BSL2 laboratory workspace, the CellNetworks Deep Sequencing Core facility, in particular D. Ibberson, for cDNA library preparation and sequencing, M. Brunner for the access to the LightCycler and S. Suhm for helping with the synthesis of $1 M 7$ and APB. H.G.M.F. thanks the Deutscher Akademischer Austausch Dienst (DAAD) for the awarded scholarship.

\section{$9 \quad$ Competing interests}

The authors declare no competing interests.

\section{Figure legends}

\section{Figure 1:}

A: Schematic representation of the cell-population-sensor Agr locus in S. aureus. AgrD is a precursor peptide that is converted into an autoinducing peptide (AIP) upon proteolysis by AgrB (transmembrane protein) and secreted to the exterior. The AIP then binds to the AgrC receptor, triggering autophosphorylation of its intracellular histidine kinase domain. AgrA is activated by the transfer of the phosphate group of AgrC and enhances transcription of $\mathrm{P} 2$ and $\mathrm{P} 3$ promoters, leading to RNAll and RNAlll production. RNAll encodes all the Agr proteins (AgrB/D/C/A) whereas RNAIII is a regulatory RNA also containing an ORF encoding for delta-toxin (HId) (See text for more details). B: Scatter plot of NGS data after NAD captureSeq. Y-axis represents the enrichment of RNAs (Log2 Fold change) in the fully treated samples against minus ADPRC (control). The X-axis shows the average of normalized counts. The dots confined in the upper right region of the plot represent the RNAs significantly enriched (NAD-capped RNAs). The light green dots depict the hits 
777 clustering at the $5^{\prime}$-UTR and with $+1 \mathrm{~A}$. A light green star represents the hld/RNAlll gene, which is

778 the most enriched by far, whereas RNAll (depicted by a red star) is located in the non-enriched

779 area of the graph.

780 C: Distribution of normalized reads on the hld/RNAlll gene (grey bar) visualized with the 781 Integrated Genome Browser (Nicol et al., 2009). The sample reads (shown in blue) are the 782 normalized reads of the ADPRC-treated sample group whereas the red-labeled control reads are 783 the ADPRC-negative. The orientation of the gene is indicated in the black bar above and 784 represents the coding strand (+). RPM: Reads per million mapped reads.

785 D: Bar chart representing the enrichment at the cDNA level of three targeted regions of the 786 hld/RNAlll gene (5'-UTR, middle region, and 3'-region). The Y-axis represents the Cp fold change 787 (sample vs. negative control group) obtained by qPCR.

788 E: Schematic view of workflow followed for detection of NAD-RNAs in total RNA samples and 789 pulled-down RNAs.

790 F: Extracted ion chromatogram representing the pull-down LC-MS outcome. The Y-axis 791 represents the NAD ( $r-N A$ ) intensity of RNAIII (green, from 40 ng RNA) and 5SrRNA (blue, negative 792 control, from 960 ng RNA). The X-axis indicates the retention time in minutes. The table beneath 793 shows the concentration of r-NA (NAD) per ng RNA and also the NAD modification percentage 794 for each RNA.

795 
Figure 2:

A: Promoter sequences of the different pCG-246-derivated constructs used in the study (pCG-P3, pCG-P3(-1G), and pCG-P2). Highlighted are the -35 (-35, purple for P3 and light gray for P2), -10

$800 \quad(-10$, brown for P3 and orange for P2) and -1 (-1, light blue for native P3, pink for mutated P3 and 801 black for native P2) regions. The first four nucleotides of RNAlll are highlighted in green.

802 B: The figure shows the workflow (steps 1 to 6 ) followed for the pull-down of specific RNA targets 803 and the subsequent RNA cleavage by a DNAzyme (see text for more information).

804 C: Analysis of pulled-down RNAIII by Northern blot on APBgels after DNAzyme treatment of the 805 different S. aureus strains (pCG-P3, pCG-P3(-1G), and pCG-P2, each of them by triplicate). The 806 arrows indicate the bands belonging to NAD-RNAIII and ppp-RNAIII 5'-termini. As a marker, $10 \mathrm{ng}$ 807 of in vitro-transcribed (IVT) ppp-RNAIII treated with DNAzyme were loaded in the first lane from 808 the left. Control samples underwent a NudC treatment before analysis on APBgels. The marker 809 used was mixed NAD/ppp-RNAlll instead of ppp-RNAlll. The bar chart beneath depicts the 810 quantification of NAD-modification ratio of RNAlll of S. aureus pCG-P3 (black) and pCG-P3(-1G) 811 (blue), based on the Northern blot without NudC treatment. Statistical significance determined 812 by $t$-test, $\mathrm{n}=5$.

813 D: The chart represents the enrichment (capture efficiency) of each of the IS NAD-RNAs in the 814 three NAD captureSeq experiments conducted: $S$ aureus pCG-P3 (black dot and line), pCG-P3(815 1G) (blue square and line) and pCG-P2 (red triangle and line).

816 E: Scatter plot of NGS data after NAD captureSeq. Y-axis represents the enrichment of $h / d /$ RNAIII 817 gene (log2fold change) in the fully treated samples against minus ADPRC (control). The $X$-axis 818 shows the average of normalised counts. Each strain is represented with markers: a black dot for 819 pCG-P3, blue triangle for pCG-P3(-1G), and red square for pCG-P2. The bar chart on the right side 820 shows the RNAlll enrichment in terms of fold change (sample vs negative control) of pCG-P3 821 (black bar) and pCG-P3(-1G) (blue bar) S. aureus strains. Statistical significance determined by $t$ 822 test, $\mathrm{n}=6$.

823 F: The figure shows the ligated $3^{\prime}$-UTR and 5'-UTR of circularised RNAs (cRNA). Sequences were 824 obtained by Sanger sequencing after cRT-PCR (see Methods).

$825 P<0.05 ; *, P<0.0001 ; * * * *$. Horizontal bars represent mean. Error bars depict standard 826 deviation. 


\section{Figure 3:}

830 A: Cleavage of NAD-RNAIll by NudC. The reactions were analysed on APBgels. The bands 831 represent radiolabeled (body labelled) NAD-RNAIII and p-RNAIII. Incubation controls withouth 832 enzyme (NC) were included. \#1, \#2, and \#3 depict the three replicates. Highlighted in red and 833 green are the percentages of NAD-RNAIII and pRNA after incubation. RNA folding plus the 834 addition of fresh NudC afterwards was done to equilibrate the RNAIII secondary structure pool 835 again.

836 B: RNAIII levels in the three different strains measured by qPCR. Y-axis represents the relative 837 expression of $h / d$ divided by the relative expression of the housekeeping gene gyr $B$. Statistical 838 significance determined by $t$-test, $n=6$. C: The two scatter plots show the total amount of Hld and Hla in the supernatant of S. aureus pCG-P3 and pCG-P3(-1G) strains. The Hld intensity was calculated by integration of the two 841 highest $M S$ peaks: Hld $\mathrm{m} / \mathrm{z}=993.5$ and its formylated version $\mathrm{m} / \mathrm{z}=1002.9$. Alpha-toxin was 842 detected by Western blotting and quantified by densitometry. Statistical significance determined 843 by $t$-test, $\mathrm{n}=6$.

844 D: Bacterial supernatants were analysed for cytotoxic potential against THP1 macrophages. 845 Percent cytotoxicity shown was normalised to the Triton control. Statistical significance 846 determined by one-way ANOVA with Tukey's post-test, $\mathrm{n}=21$.

$847 * P \leq 0.05, * * P \leq 0.01,{ }^{* * *} P \leq 0.001, * * * * P \leq 0.0001, \mathrm{~ns}$ : non-significant. WT: wild type $S$. aureus 848 HG001. Horizontal bars represent mean. 
851 Figure 4: Analysis of the secondary structure of RNAlll 5 '-end variants by SHAPE.

852 A: The bar chart represents the differential SHAPE reactivity (Y-axis) throughout the nucleotides

853 of the 5'-UTR of RNAIII (X-axis). The blue bars represent NAD-RNAIII leader whereas the light grey

854 bars represent ppp-RNAlll leader (113 nt long). The region containing the SD sequence and the

$855 \mathrm{H} 2$ loop residues are indicated as a horizontal black lines.

856 B: Bar chart showing a detailed view of the SHAPE reactivity (accessibility) of the SD sequence 857 from ppp-RNAlll leader (light grey bar) and NAD-RNAIll (blue bar). Full-length (514 nt) ppp-RNAIII 858 is represented with dark grey bars. A: adenosine, G: guanosine.

859 C: Same as panel A but the chart compares full-length ppp-RNAIII (grey bar) vs NAD/ppp-RNAIII 860 (green bar) SHAPE experiments.

861 D: Same as panel B but comparing the SD sequence accessibility of full-length ppp-RNAllI (grey 862 bar) vs NAD/ppp-RNAlll (green bar).

863 Horizontal bars represent mean. Error bars depict standard deviation. 
Figure S1:

A: Size selection step during purification of PCR-amplified libraries with NGS primers on a $10 \%$ non-denaturing PA gel stained with SYBR Gold (Thermo Fisher Scientific). The dashed lines indicate the excised area (between 150 and $300 \mathrm{bp}$ ). The numbers indicate three replicates of minus ADPRC controls. M: Ultra Low Range DNA Ladder (Thermo Fisher Scientific).

B: TSS analysis of the 21 hits enriched in NAD captureSeq in S. aureus ATCC 25923. Note that position +1 is not shown because all hits were selected to start with adenosine. A: adenosine, $T$ : thymidine, B: guanosine, C: cytidine.

874 C: Northern blot with probes against RNAlll and 5SrRNA. Ten micrograms of total RNA from S. aureus ATCC 25923 were loaded on each of the probe-hybridised lanes. Radioactively labeled RNA Century Marker (Thermo Fisher Scientific) was loaded on the first lane by the left. D: APBgels-Northern blot conducted in triplicate with total RNA of S. aureus pCG-P3 and pCG-P2 strains and probe against RNAIII. IVT Full-length mixed ppp/NAD-RNAIII was loaded as a control in the flanking lanes. Note that this experiment shows full-length RNAll with no DNAzyme treatment. \#1, \#2 and \#3 represent biological replicates. E: Membrane used for the detection of alpha-toxin ( $\mathrm{Hla}$ ) by Western blotting in culture filtrates from two strains (pCG-P3 and pCG-P3(-1G)) in triplicate (\#1, \#2 and \#3). The marker used was the PageRuler Prestained Protein Ladder (Thermo Fisher Scientific). Two arrows indicate the bands corresponding to Hla (target) and protein A (unspecific binding of the antibody). F: Stacked extracted ion chromatograms from two different strains in triplicates (blue line pCGP3(-1G), black line pCG-P3). The first peak corresponds to delta-toxin (HId) whereas the second belongs to its formylated version.

G: Analysis of SHAPE-teated RNAIII leader (in vitro). G, U, A and C represent the RNA nucleobases, which are equivalent to their cognate dideoxynucleotide used for the ladder generation. The bases of the SD sequence are highlighted in red. N: NAD-RNAIII leader treated with $1 \mathrm{M7}(+)$ or with DMSO (-), P: ppp-RNAlll leader treated with $1 \mathrm{M7}$ (+) or with DMSO (-), FL: Full length reverse transcription product (113 $\mathrm{nt}$ ). H: Agarose gel electrophoresis analysis of total RNA samples from the different $S$. aureus strains. Total RNA was isolated and treated with DNasel as described in the methods section. M: $1 \mathrm{~Kb}$ Plus DNA Ladder (Thermo Fisher Scientific). Numbers indicate three replicates of each strain. I: Northern Blot of RNA pull-down eluates before PAGE purification. Samples were hybridised with RNAIII and 5SrRNA radiolabeled probes. (PD RNAIII) and 5SrRNA (PD 5S). As a size marker ppp-RNAll, I was loaded, together with Riboruler Low Range RNA Ladder (Thermo Fisher Scientific). The red dashed areas indicate the excised region of the gels, corresponding to RNAlll and 5SrRNA.

903

K: LC/MS-ready (after PAGE purification and band excision) RNAlll and 5SrRNA were subjected to Northern Blot detection. RNAllI concentration was too low to be detected.

905 L: Screening of different DNAzymes (I, II, and III) on mixed ppp/NAD-RNAIII. The figure shows a Northern blot targeting RNAIII (probe complementary to first 86 nt of RNAIII), after electrophoresis on $8 \%$ polyacrylamide gel (left side) and APBgel (right side). The same ppp/NADRNAIll was loaded without treatment in both gels as a marker. The APB gel shows the separation between NAD and ppp RNAIII 5' - fragments. DNAzyme II is the most active of the three, acting quantitatively. 
M: Analysis of purified NAD / ppp-RNAlll leader on an APBgel. The ladder used was Riboruler Low Range RNA Ladder (Thermo Fisher Scientific).

\section{References}

915

916

917

918

919

920

921

922

923

924

925

926

927

928

929

930

931

932

933

934

935

936

937

938

939

940

941

942

943

944

945

946

947

948

949

950

951

952

953

Alwine, J. C., Kemp, D. J., \& Stark, G. R. (1977). Method for detection of specific RNAs in agarose gels by transfer to diazobenzyloxymethyl-paper and hybridization with DNA probes. Proc Natl Acad Sci U S A, 74(12), 5350-5354.

Anders, S., \& Huber, W. (2010). Differential expression analysis for sequence count data. Genome Biol, 11(10), R106. doi:10.1186/gb-2010-11-10-r106

Anders, S., Pyl, P. T., \& Huber, W. (2015). HTSeq--a Python framework to work with highthroughput sequencing data. Bioinformatics, 31(2), 166-169. doi:10.1093/bioinformatics/btu638

Balaban, N., \& Novick, R. P. (1995). Translation of RNAIII, the Staphylococcus aureus agr regulatory RNA molecule, can be activated by a 3'-end deletion. FEMS Microbiol Lett, 133(1-2), 155-161. doi:10.1111/j.1574-6968.1995.tb07877.x

Benito, Y., Kolb, F. A., Romby, P., Lina, G., Etienne, J., \& Vandenesch, F. (2000). Probing the structure of RNAIII, the Staphylococcus aureus agr regulatory RNA, and identification of the RNA domain involved in repression of protein A expression. RNA, 6(5), 668-679. doi:10.1017/s1355838200992550

Bird, J. G., Zhang, Y., Tian, Y., Panova, N., Barvik, I., Greene, L., . . Nickels, B. E. (2016). The mechanism of RNA 5' capping with NAD+, NADH and desphospho-CoA. Nature, 535(7612), 444-447. doi:10.1038/nature18622

Boisset, S., Geissmann, T., Huntzinger, E., Fechter, P., Bendridi, N., Possedko, M., . . Romby, P. (2007). Staphylococcus aureus RNAIII coordinately represses the synthesis of virulence factors and the transcription regulator Rot by an antisense mechanism. Genes Dev, 21(11), 1353-1366. doi:10.1101/gad.423507

Bronesky, D., Wu, Z., Marzi, S., Walter, P., Geissmann, T., Moreau, K., . . Romby, P. (2016). Staphylococcus aureus RNAIII and Its Regulon Link Quorum Sensing, Stress Responses, Metabolic Adaptation, and Regulation of Virulence Gene Expression. Annu Rev Microbiol, 70, 299-316. doi:10.1146/annurev-micro-102215-095708

Cahová, H., Winz, M. L., Höfer, K., Nübel, G., \& Jäschke, A. (2015). NAD captureSeq indicates NAD as a bacterial cap for a subset of regulatory RNAs. Nature, 519(7543), 374-377. doi:10.1038/nature 14020

Charpentier, E., Anton, A. I., Barry, P., Alfonso, B., Fang, Y., \& Novick, R. P. (2004). Novel cassette-based shuttle vector system for gram-positive bacteria. Appl Environ Microbiol, 70(10), 6076-6085. doi:10.1128/aem.70.10.6076-6085.2004

Chen, Y. G., Kowtoniuk, W. E., Agarwal, I., Shen, Y., \& Liu, D. R. (2009). LC/MS analysis of cellular RNA reveals NAD-linked RNA. Nat Chem Biol, 5(12), 879-881. doi: $10.1038 /$ nchembio. 235

David, M. Z., \& Daum, R. S. (2010). Community-associated methicillin-resistant Staphylococcus aureus: epidemiology and clinical consequences of an emerging epidemic. Clin Microbiol Rev, 23(3), 616-687. doi:10.1128/CMR.00081-09 
954

955

956

957

958

959

960

961

962

963

964

965

966

967

968

969

970

971

972

973

974

975

976

977

978

979

980

981

982

983

984

985

986

987

988

989

990

991

992

993

994

995

996

997

998

Frick, D. N., \& Bessman, M. J. (1995). Cloning, purification, and properties of a novel NADH pyrophosphatase. Evidence for a nucleotide pyrophosphatase catalytic domain in MutTlike enzymes. Journal of Biological Chemistry, 270(4), 1529-1534.

Frindert, J., Zhang, Y., Nubel, G., Kahloon, M., Kolmar, L., Hotz-Wagenblatt, A., . . Jaschke, A. (2018). Identification, Biosynthesis, and Decapping of NAD-Capped RNAs in B. subtilis. Cell Rep, 24(7), 1890-1901 e1898. doi:10.1016/j.celrep.2018.07.047

Garcia-Betancur, J. C., Goni-Moreno, A., Horger, T., Schott, M., Sharan, M., Eikmeier, J., . . . Lopez, D. (2017). Cell differentiation defines acute and chronic infection cell types in Staphylococcus aureus. Elife, 6. doi:10.7554/eLife.28023

Geisinger, E., Adhikari, R. P., Jin, R., Ross, H. F., \& Novick, R. P. (2006). Inhibition of rot translation by RNAIII, a key feature of agr function. Mol Microbiol, 61(4), 1038-1048. doi:10.1111/j.1365-2958.2006.05292.x

Helle, L., Kull, M., Mayer, S., Marincola, G., Zelder, M. E., Goerke, C., . . Bertram, R. (2011). Vectors for improved Tet repressor-dependent gradual gene induction or silencing in Staphylococcus aureus. Microbiology, 157(Pt 12), 3314-3323. doi:10.1099/mic.0.0525480

Höfer, K., Abele, F., Schlotthauer, J., \& Jäschke, A. (2016). Synthesis of 5 '-NAD-Capped RNA. Bioconjugate Chemistry, 27(4), 874-877. doi:10.1021/acs.bioconjchem.6b00072

Howarth, M., Takao, K., Hayashi, Y., \& Ting, A. Y. (2005). Targeting quantum dots to surface proteins in living cells with biotin ligase. Proc Natl Acad Sci U S A, 102(21), 7583-7588. doi:10.1073/pnas.0503125102

Huang, F. (2003). Efficient incorporation of CoA, NAD and FAD into RNA by in vitro transcription. Nucleic Acids Research, 31(3), e8.

Huntzinger, E., Boisset, S., Saveanu, C., Benito, Y., Geissmann, T., Namane, A., . . Romby, P. (2005). Staphylococcus aureus RNAIII and the endoribonuclease III coordinately regulate spa gene expression. Embo Journal, 24(4), 824-835. doi:10.1038/sj.emboj.7600572

Igloi, G. L., \& Kossel, H. (1985). Affinity electrophoresis for monitoring terminal phosphorylation and the presence of queuosine in RNA. Application of polyacrylamide containing a covalently bound boronic acid. Nucleic acids research, 13(19), 6881-6898. doi:10.1093/nar/13.19.6881

Janzon, L., \& Arvidson, S. (1990). The Role of the Delta-Lysin Gene (Hld) in the Regulation of Virulence Genes by the Accessory Gene Regulator (Agr) in Staphylococcus-Aureus. Embo Journal, 9(5), 1391-1399.

Janzon, L., Lofdahl, S., \& Arvidson, S. (1989). Identification and nucleotide sequence of the deltalysin gene, hld, adjacent to the accessory gene regulator (agr) of Staphylococcus aureus. Mol Gen Genet, 219(3), 480-485.

Jaschke, A., Hofer, K., Nubel, G., \& Frindert, J. (2016). Cap-like structures in bacterial RNA and epitranscriptomic modification. Curr Opin Microbiol, 30, 44-49. doi:10.1016/j.mib.2015.12.009

Jiao, X., Doamekpor, S. K., Bird, J. G., Nickels, B. E., Tong, L., Hart, R. P., \& Kiledjian, M. (2017). 5' End Nicotinamide Adenine Dinucleotide Cap in Human Cells Promotes RNA Decay through DXO-Mediated deNADding. Cell, 168(6), 1015-1027 e1010. doi:10.1016/j.cell.2017.02.019

Joyce, G. F. (2001). RNA cleavage by the 10-23 DNA enzyme. Methods Enzymol, 341, 503-517. doi:10.1016/s0076-6879(01)41173-6 
Kellner, S., Neumann, J., Rosenkranz, D., Lebedeva, S., Ketting, R. F., Zischler, H., . . Helm, M.

1000

1001

1002

1003

1004

1005

1006

1007

1008

1009

1010

1011

1012

1013

1014

1015

1016

1017

1018

1019

1020

1021

1022

1023

1024

1025

1026

1027

1028

1029

1030

1031

1032

1033

1034

1035

1036

1037

1038

1039

1040

1041

1042

1043 (2014). Profiling of RNA modifications by multiplexed stable isotope labelling. Chem Commun (Camb), 50(26), 3516-3518. doi:10.1039/c3cc49114e

Koenig, R. L., Ray, J. L., Maleki, S. J., Smeltzer, M. S., \& Hurlburt, B. K. (2004). Staphylococcus aureus AgrA binding to the RNAIII-agr regulatory region. J Bacteriol, 186(22), 75497555. doi:10.1128/JB.186.22.7549-7555.2004

Laederach, A., Das, R., Vicens, Q., Pearlman, S. M., Brenowitz, M., Herschlag, D., \& Altman, R. B. (2008). Semiautomated and rapid quantification of nucleic acid footprinting and structure mapping experiments. Nature Protocols, 3(9), 1395-1401. doi:10.1038/nprot.2008.134

Li, H. (2013). Aligning sequence reads, clone sequences and assembly contigs with BWA-MEM. ArXiv, 1303.

Li, M., Diep, B. A., Villaruz, A. E., Braughton, K. R., Jiang, X., DeLeo, F. R., . . Otto, M. (2009). Evolution of virulence in epidemic community-associated methicillin-resistant Staphylococcus aureus. Proc Natl Acad Sci $U$ S A, 106(14), 5883-5888. doi:10.1073/pnas.0900743106

Lioliou, E., Fechter, P., Caldelari, I., Jester, B. C., Dubrac, S., Helfer, A.-C., . . Geissmann, T. (2016). Various checkpoints prevent the synthesis of Staphylococcus aureus peptidoglycan hydrolase LytM in the stationary growth phase. RNA Biology, 13(4), 427-440. doi:10.1080/15476286.2016.1153209

Livak, K. J., \& Schmittgen, T. D. (2001). Analysis of relative gene expression data using real-time quantitative PCR and the 2(-Delta Delta C(T)) Method. Methods, 25(4), 402-408. doi:10.1006/meth.2001.1262

Lowy, F. D. (1998). Medical progress - Staphylococcus aureus infections. New England Journal of Medicine, 339(8), 520-532. doi:Doi 10.1056/Nejm199808203390806

Morfeldt, E., Taylor, D., von Gabain, A., \& Arvidson, S. (1995). Activation of alpha-toxin translation in Staphylococcus aureus by the trans-encoded antisense RNA, RNAIII. Embo Journal, 14(18), 4569-4577.

Mortimer, S. A., \& Weeks, K. M. (2007). A fast-acting reagent for accurate analysis of RNA secondary and tertiary structure by SHAPE chemistry. J Am Chem Soc, 129(14), 41444145. doi:10.1021/ja0704028

Munzenmayer, L., Geiger, T., Daiber, E., Schulte, B., Autenrieth, S. E., Fraunholz, M., \& Wolz, C. (2016). Influence of Sae-regulated and Agr-regulated factors on the escape of Staphylococcus aureus from human macrophages. Cell Microbiol, 18(8), 1172-1183. doi:10.1111/cmi.12577

Nicol, J. W., Helt, G. A., Blanchard, S. G., Jr., Raja, A., \& Loraine, A. E. (2009). The Integrated Genome Browser: free software for distribution and exploration of genome-scale datasets. Bioinformatics, 25(20), 2730-2731. doi:10.1093/bioinformatics/btp472

Novick, R. P., Projan, S. J., Kornblum, J., Ross, H. F., Ji, G., Kreiswirth, B., . . Novick, R. P. (1995). The agr P2 operon: An autocatalytic sensory transduction system in Staphylococcus aureus. Molecular and General Genetics MGG, 248(4), 446-458. doi:10.1007/bf02191645

Novick, R. P., Ross, H. F., Projan, S. J., Kornblum, J., Kreiswirth, B., \& Moghazeh, S. (1993). Synthesis of Staphylococcal Virulence Factors Is Controlled by a Regulatory Rna Molecule. Embo Journal, 12(10), 3967-3975. 
1044

1045

1046

1047

1048

1049

1050

1051

1052

1053

1054

1055

1056

1057

1058

1059

1060

1061

1062

1063

1064

1065

1066

1067

1068

1069

1070

1071

1072

1073

1074

1075

1076

1077

1078

1079

1080

1081

1082

1083

1084

1085

1086

1087

1088

Nübel, G., Sorgenfrei, F. A., \& Jäschke, A. (2017). Boronate affinity electrophoresis for the purification and analysis of cofactor-modified RNAs. Methods, 117, 14-20. doi:10.1016/j.ymeth.2016.09.008

Paharik, A. E., Salgado-Pabon, W., Meyerholz, D. K., White, M. J., Schlievert, P. M., \& Horswill, A. R. (2016). The Spl Serine Proteases Modulate Staphylococcus aureus Protein Production and Virulence in a Rabbit Model of Pneumonia. mSphere, 1(5). doi:10.1128/mSphere.00208-16

Peng, H. L., Novick, R. P., Kreiswirth, B., Kornblum, J., \& Schlievert, P. (1988). Cloning, characterization, and sequencing of an accessory gene regulator (agr) in Staphylococcus aureus. J Bacteriol, 170(9), 4365-4372.

Peschel, A., \& Otto, M. (2013). Phenol-soluble modulins and staphylococcal infection. Nature Reviews Microbiology, 11, 667. doi:10.1038/nrmicro3110

Quave, C. L., Lyles, J. T., Kavanaugh, J. S., Nelson, K., Parlet, C. P., Crosby, H. A., . . Horswill, A. R. (2016). Correction: Castanea sativa (European Chestnut) Leaf Extracts Rich in Ursene and Oleanene Derivatives Block Staphylococcus aureus Virulence and Pathogenesis without Detectable Resistance. PLoS One, 11(9), e0163655. doi:10.1371/journal.pone.0163655

Queck, S. Y., Jameson-Lee, M., Villaruz, A. E., Bach, T. H., Khan, B. A., Sturdevant, D. E., ... Otto, M. (2008). RNAIII-independent target gene control by the agr quorum-sensing system: insight into the evolution of virulence regulation in Staphylococcus aureus. Mol Cell, 32(1), 150-158. doi:10.1016/j.molcel.2008.08.005

Recsei, P., Kreiswirth, B., O'Reilly, M., Schlievert, P., Gruss, A., \& Novick, R. P. (1986). Regulation of exoprotein gene expression in Staphylococcus aureus by agar. Mol Gen Genet, 202(1), 58-61.

Reed, S. B., Wesson, C. A., Liou, L. E., Trumble, W. R., Schlievert, P. M., Bohach, G. A., \& Bayles, K. W. (2001). Molecular Characterization of a Novel Staphylococcus aureus Serine Protease Operon. Infection and Immunity, 69(3), 1521-1527. doi:10.1128/iai.69.3.1521-1527.2001

Reuter, J. S., \& Mathews, D. H. (2010). RNAstructure: software for RNA secondary structure prediction and analysis. BMC Bioinformatics, 11, 129. doi:10.1186/1471-2105-11-129

Reynolds, J., \& Wigneshweraraj, S. (2011). Molecular insights into the control of transcription initiation at the Staphylococcus aureus agr operon. J Mol Biol, 412(5), 862-881. doi:10.1016/j.jmb.2011.06.018

Said-Salim, B., Dunman, P. M., McAleese, F. M., Macapagal, D., Murphy, E., McNamara, P. J., . . Kreiswirth, B. N. (2003). Global regulation of Staphylococcus aureus genes by Rot. $J$ Bacteriol, 185(2), 610-619. doi:10.1128/jb.185.2.610-619.2003

Slomovic, S., \& Schuster, G. (2013). Circularized RT-PCR (cRT-PCR): analysis of the 5' ends, 3' ends, and poly(A) tails of RNA. Methods Enzymol, 530, 227-251. doi:10.1016/B978-0-12420037-1.00013-0

Traber, K. E., Lee, E., Benson, S., Corrigan, R., Cantera, M., Shopsin, B., \& Novick, R. P. (2008). agr function in clinical Staphylococcus aureus isolates. Microbiology, 154(Pt 8), 22652274. doi:10.1099/mic.0.2007/011874-0

Vvedenskaya, I. O., Bird, J. G., Zhang, Y., Zhang, Y., Jiao, X., Barvik, I., . . Nickels, B. E. (2018). CapZyme-Seq Comprehensively Defines Promoter-Sequence Determinants for RNA 5' Capping with NAD+. Mol Cell, 70(3), 553-564 e559. doi:10.1016/j.molcel.2018.03.014 
Walters, R. W., Matheny, T., Mizoue, L. S., Rao, B. S., Muhlrad, D., \& Parker, R. (2017). Identification of NAD+ capped mRNAs in Saccharomyces cerevisiae. Proc Natl Acad Sci $U S$ A, 114(3), 480-485. doi:10.1073/pnas.1619369114

Wang, Y., Li, S., Zhao, Y., You, C., Le, B., Gong, Z., . . Chen, X. (2019). NAD(+)-capped RNAs

1093

1094 are widespread in the Arabidopsis transcriptome and can probably be translated. Proc Natl Acad Sci U S A. doi:10.1073/pnas.1903682116 
bioRxiv preprint doi: https://doi.org/10.1101/778233; this version posted September 24, 2019. The copyright holder for this preprint (which was not certified by peer review) is the author/funder, who has granted bioRxiv a license to display the preprint in perpetuity. It is made available under aCC-BY-NC-ND 4.0 International license.

A

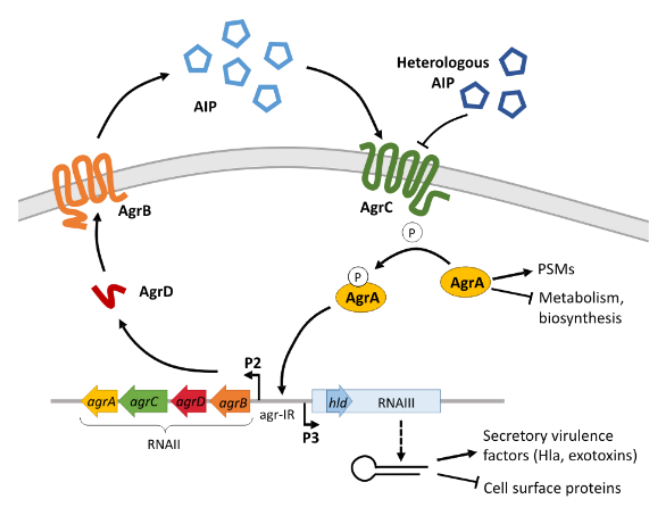

C Mapping of NGS reads to 5'end of hld/RNAIII

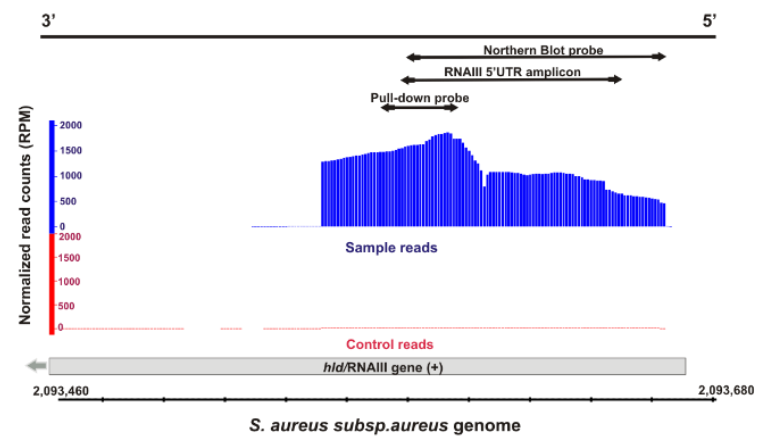

$\mathrm{E}$
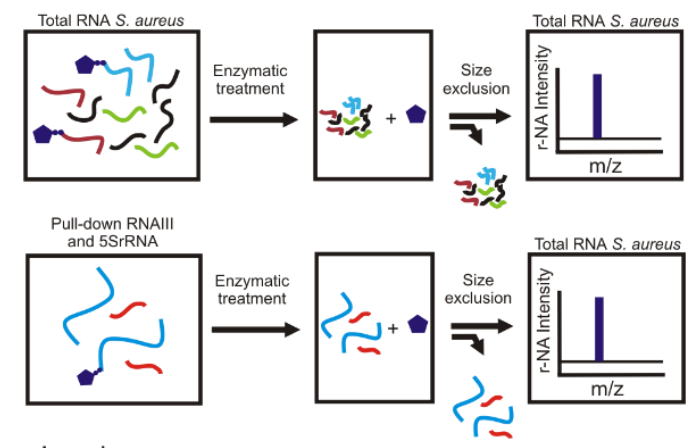

1109

1110
B

Identification of NAD-capped RNAs by NGS

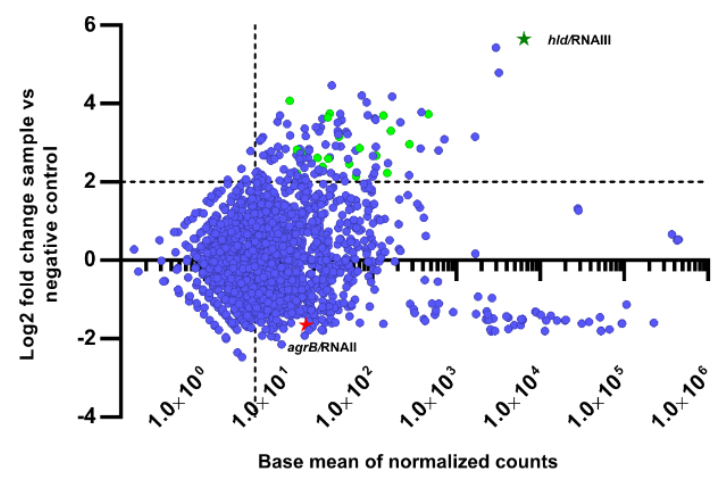

$\mathrm{D}$

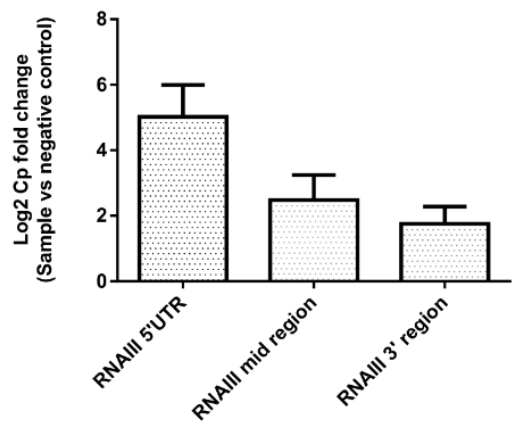

F

MS analysis of pull-down RNAIII

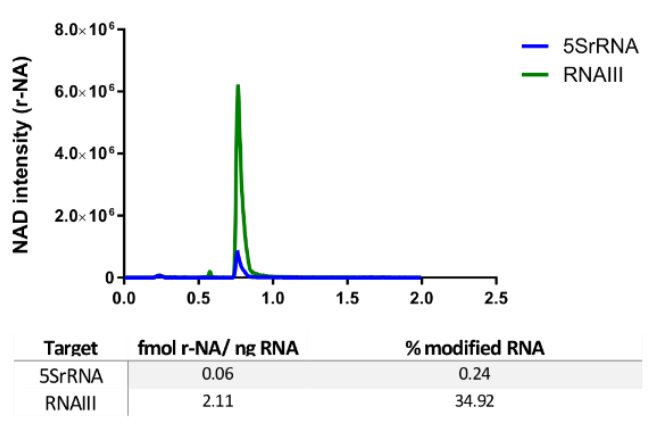


bioRxiv preprint doi: https://doi.org/10.1101/778233; this version posted September 24, 2019. The copyright holder for this preprint (which was not certified by peer review) is the author/funder, who has granted bioRxiv a license to display the preprint in perpetuity. It is made available under aCC-BY-NC-ND 4.0 International license.

1111

A

$$
\begin{aligned}
& \text { P3 promoter AATTGGAAAATAAATGCTTTtAagCATGTTTTAATATAACTAGAT } \\
& \text { pCG-P3 AATTGGAAATAAATGCTTTTAGCATGTTTTTAATATAACTAGAT } \\
& \text { pCG-P3(-1G) } \begin{array}{c}
-35 \\
\text { AATTGGAAAATAAATGCTTTTAGCATGTTTTAATATAACGAGAT }
\end{array} \\
& \text { pCG-P2 TA }{ }^{-35} \text { AAAGATTGTACTAAATCGTATAATGACAGTGAGAT }
\end{aligned}
$$

C Determination of RNAIII's NAD modification ratio in different $S$. aureus strains
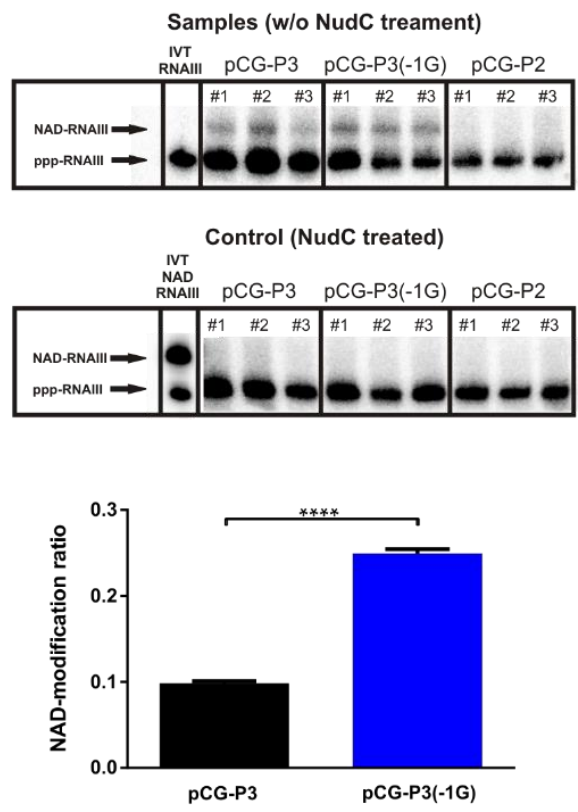

$\mathrm{F}$

\section{3}

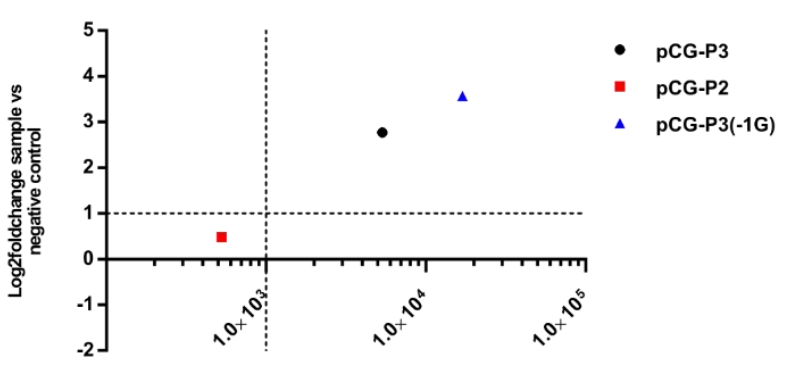

Base mean of normalized counts
B

RNA pull-down with biotinylated probes and DNAzyme treatment

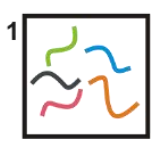

S. aureus total RNA

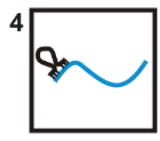

DNAzyme

DNAzyme
treatment of target
RNA

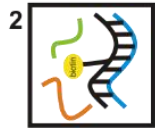

Binding of biotinylated
DNA probes to target
RNA

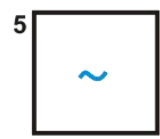

Shortened target
RNA (5' end)

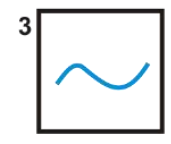

Elution of target RNA

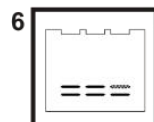

Northern Blot over
APB gels
D

Capture efficiency of IS NAD-RNAs

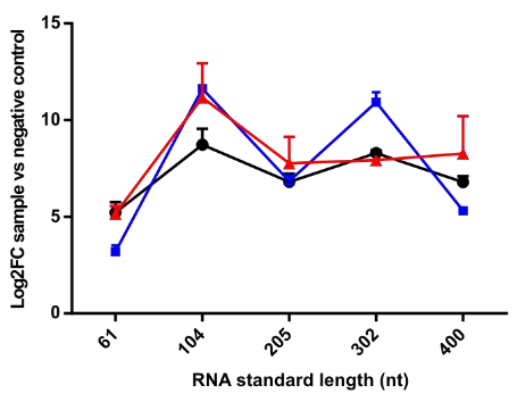

$\rightarrow$ pCG-P3

$\rightarrow$ pCG-P3(-1G)

$\simeq$ pCG-P2

$E$

Analysis of RNA 3' and 5'ends

$$
\begin{aligned}
& \text { cRNAlll under P3 promoter - } \begin{array}{l}
3^{\prime} \text { UTR } \\
\text { GCGGCCTTAEGATCACA- }
\end{array} \\
& \text { cRNAlll under P2 promoter -GCGGCCTTGAGATCACA- } \\
& \text { cRNAll under P2 promoter -GCTTTTTAGAGGAGAGT- }
\end{aligned}
$$



Fold change (sample vs negative control) 
bioRxiv preprint doi: https://doi.org/10.1101/778233; this version posted September 24, 2019. The copyright holder for this preprint (which was not certified by peer review) is the author/funder, who has granted bioRxiv a license to display the preprint in perpetuity. It is made available under aCC-BY-NC-ND 4.0 International license.

1114

A

NudC cleavage of NAD-RNAIII
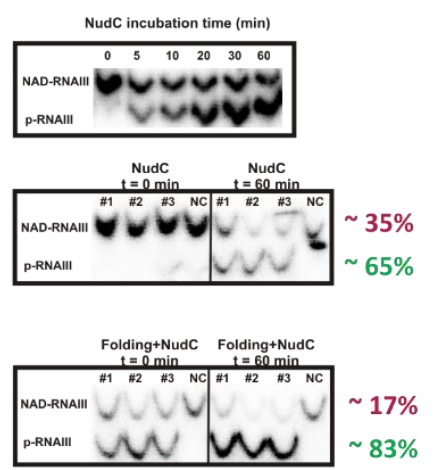

C

Exotoxin analysis of the different $S$. aureus strains

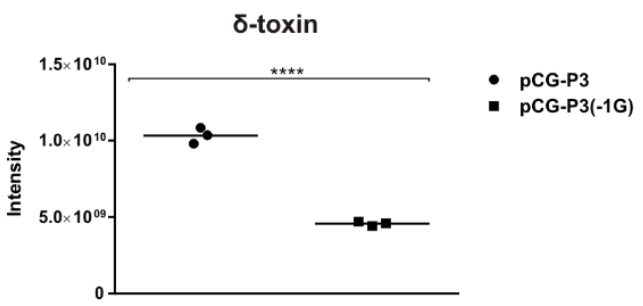

1115

\section{6}

B

Quantification of RNAIll levels by qPCR

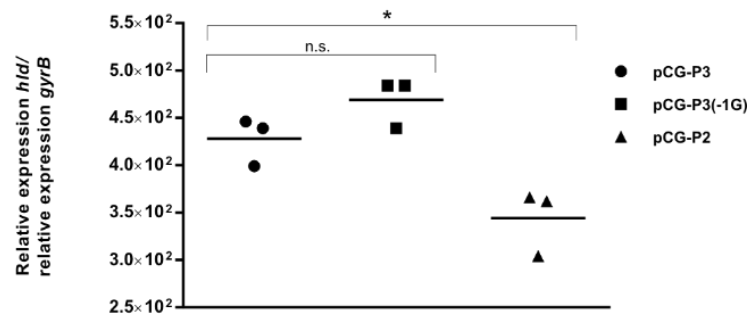

$\mathrm{D}$

Cytotoxic assay of S. aureus strains on THP1 cells

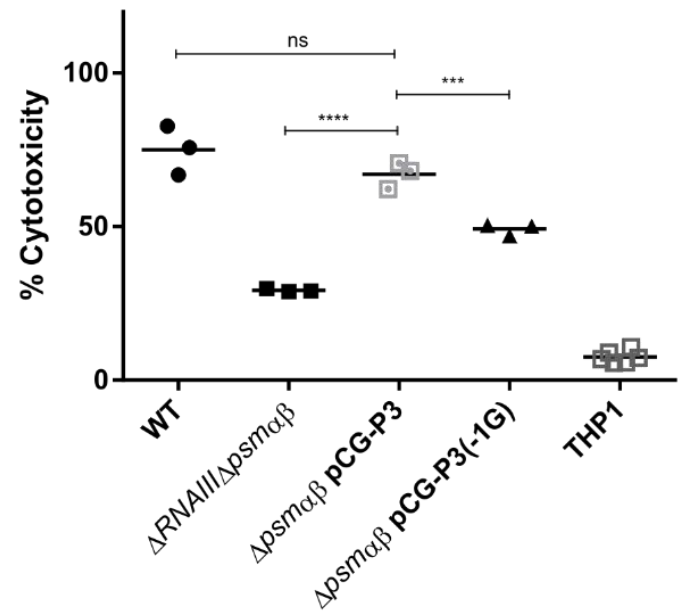


A SHAPE reactivity profiles of RNAIII leader 5'-end variants

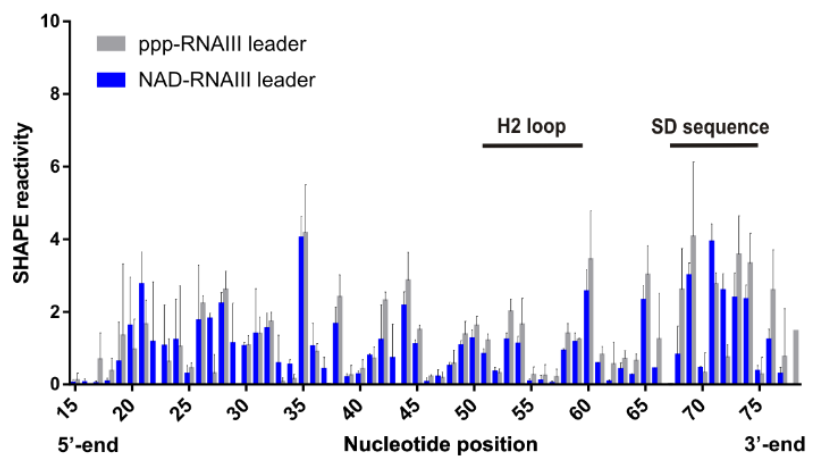

C SHAPE reactivity profiles of RNAIII (full-length) 5'-end variants

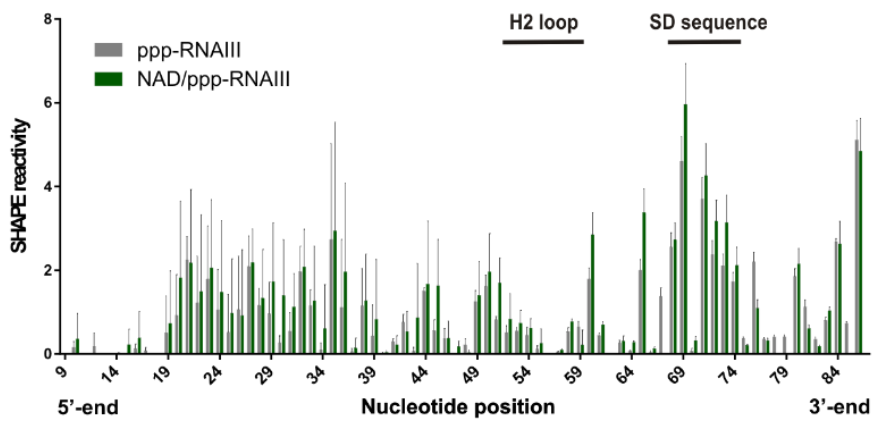

Figure 4

\section{Supplementary tables} per cell.
B

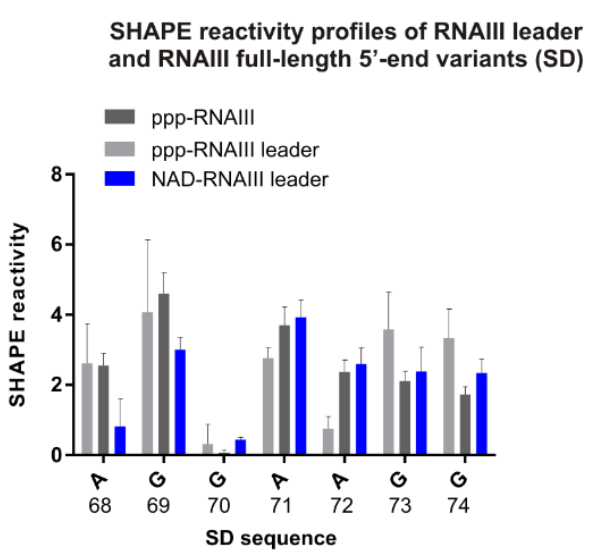

SHAPE reactivity profiles of RNAIII (full-length) 5 '-end variants (SD)

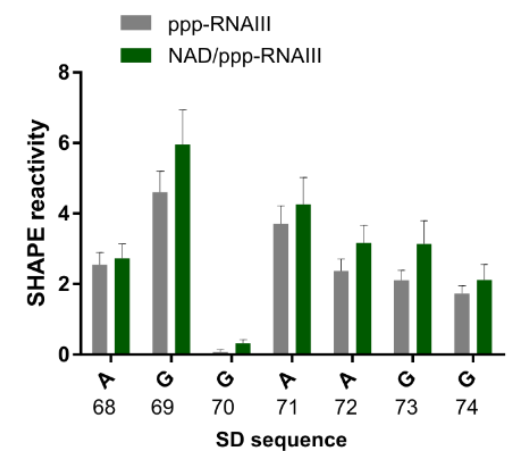

Table S1: Detection of NAD by UPLC/MS/MS in total RNA samples from S. aureus. I and II: reactions by duplicate performed with NudC. Column 2 shows the NudC-treated samples minus the negative control (non-treated). The third column shows the estimated NAD-RNA molecules

\begin{tabular}{|c|c|c|c|}
\hline & Sample (fmol NAD/ $\mu \mathrm{g}$ RNA) & $\begin{array}{l}\text { Sample - negative control } \\
\text { (fmol NAD/ } \mu \text { g RNA) }\end{array}$ & Estimated NAD-RNA molecules per cell \\
\hline S. aureus I & 31.52 & 23.61 & 839 \\
\hline S. aureus II & 34.81 & 26.89 & 955 \\
\hline
\end{tabular}


1127 Table S2: Enriched hits after NAD captureSeq in S. aureus ATCC 25923 strain. Base mean:

1128 normalised mapped reads, Log2FC: Log2 Fold change (sample vs negative control).

\begin{tabular}{|l|l|r|r|r|}
\hline Gene annotation number & Gene product & Base mean & Log2FC & $\boldsymbol{P}$-value \\
\hline SAOUHSC_00070 & HTH-type transcriptional regulator SarS & 63.88 & 2.15 & 0.016 \\
\hline SAOUHSC_00086 & 3-ketoacyl-acyl carrier protein reductase putative & 166.37 & 3.30 & 0.000 \\
\hline SAOUHSC_00204 & Globin domain protein & 111.18 & 2.67 & 0.002 \\
\hline SAOUHSC_00615 & Haloacid dehalogenase-like hydrolase putative & 39.83 & 3.15 & 0.002 \\
\hline SAOUHSC_00781 & HPr kinase/phosphorylase & 25.40 & 2.39 & 0.022 \\
\hline SAOUHSC_00834 & Thioredoxin putative & 12.54 & 2.82 & 0.011 \\
\hline SAOUHSC_00861 & Lipoyl synthase & 52.53 & 2.47 & 0.010 \\
\hline SAOUHSC_01162 & Lipoprotein signal peptidase & 10.36 & 4.07 & 0.000 \\
\hline SAOUHSC_01176 & Guanylate kinase & 25.63 & 2.28 & 0.032 \\
\hline SAOUHSC_01406 & Acylphosphatase & 14.93 & 2.70 & 0.008 \\
\hline SAOUHSC_01617 & Arginine repressor & 31.13 & 3.74 & 0.000 \\
\hline SAOUHSC_01685 & Heat-inducible transcription repressor HrcA & 464.91 & 3.73 & 0.000 \\
\hline SAOUHSC_02118 & Glutamyl-tRNA(Gln) amidotransferase subunit & 29.51 & 3.65 & 0.000 \\
\hline SAOUHSC_02260 & Delta-hemolysin precursor/RNAllI & 6404.64 & 5.64 & 0.000 \\
\hline SAOUHSC_02270 & Ammonium transporter & 12.55 & 2.22 & 0.047 \\
\hline SAOUHSC_02577 & Putative 2-hydroxyacid dehydrogenase & 276.48 & 2.96 & 0.001 \\
\hline SAOUHSC_02696 & FmhA protein putative & 70.17 & 2.86 & 0.002 \\
\hline SAOUHSC_02920 & 2-dehydropantoate 2-reductase & 135.44 & 3.70 & 0.000 \\
\hline SAOUHSC_02922 & L-lactate dehydrogenase & 149.88 & 2.23 & 0.022 \\
\hline SAOUHSC_02942 & Anaerobic ribonucleoside-triphosphate reductase & 22.16 & 2.61 & 0.008 \\
\hline SAOUHSC_03045 & putative & 29.67 & 2.60 & 0.009 \\
\hline & Cold shock protein putative & & \\
\hline
\end{tabular}


1130 Table S3: Oligonucleotides used in this study

\begin{tabular}{|c|c|c|}
\hline Primer name & Sequence (5'-3') & Application \\
\hline $\begin{array}{l}\text { Fwd-P3- } \\
\text { RNAIII }\end{array}$ & $\begin{array}{l}\text { CGCGCGGATCCCATAAAAAAATTTACAGTTAAGA } \\
\text { ATAAAAAACG }\end{array}$ & pCG-671 cloning \\
\hline Rv-P3-RNAIII & GCGCGAATTCAAGGCCGCGAGCTTG & pCG-671 cloning \\
\hline Fwd-P2 & $\begin{array}{l}\text { GCGCGCGGATCCACAAATTACATTTAACAGTTAA } \\
\text { G }\end{array}$ & pCG-672 cloning \\
\hline Rv-P2hyb & $\begin{array}{l}\text { CCATCACATCTCTGTGATCTCACTGTCATTATACG } \\
\text { ATTTAG }\end{array}$ & pCG-672 cloning \\
\hline Fwd-RNAIII & AGATCACAGAGATGTGATGG & pCG-672 cloning \\
\hline Rv-RNAIII & GCGCGAATTCAAGGCCGCGAGC & pCG-672 cloning \\
\hline Mut FW & GTTATATTAAAACATGCT & pCG-673 cloning \\
\hline Mut -1G RV & GAGATCACAGAGATG & pCG-673 cloning \\
\hline $\begin{array}{l}\text { RNAlll term } \\
\text { insertion FW }\end{array}$ & TAATGAGGCGCGCCTATTC & $\begin{array}{l}\text { pCG-692, pCG-693 and pCG-694 cloning, } \\
\text { introduction native RNAlll terminator }\end{array}$ \\
\hline $\begin{array}{l}\text { RNAlll term } \\
\text { insertion RV }\end{array}$ & CAAAAAAGGCCGCGAGCTT & $\begin{array}{l}\text { pCG-692, pCG-693 and pCG-694 cloning, } \\
\text { introduction native RNAlll terminator }\end{array}$ \\
\hline $\begin{array}{l}\text { RNAIII 5'UTR } \\
\text { FW }\end{array}$ & GTGATGGAAAATAGTTGATGAGT & qPCR \\
\hline $\begin{array}{l}\text { RNAIII 5'UTR } \\
\text { RV }\end{array}$ & GCCATTGAAATCACTCCTTCC & $\mathrm{qPCR}$ \\
\hline $\begin{array}{l}\text { RNAlll mid } \\
\text { FW }\end{array}$ & GAGTTAGTTTCCTTGGACTCAG & qPCR \\
\hline RNAIll mid RV & GTTGTTTACGATAGCTTACATGC & qPCR \\
\hline RNAIII 3' FW & GCATGTAAGCTATCGTAAACAAC & qPCR \\
\hline RNAIII 3' RV & AGGGGCTCACGACCATACTT & qPCR \\
\hline 5S rRNA FW & TATAGCAAGGAGGTCACACCT & qPCR \\
\hline 5S rRNA RV & CTACCATCGACGCTAAGGAG & qPCR \\
\hline gyrB FW & CAAATGATCACAGCATTTGGTACAG & qPCR \\
\hline gyrB RV & CGGCATCAGTCATAATGACGAT & qPCR \\
\hline $\begin{array}{l}\text { RNAIII NB } \\
\text { probe FW }\end{array}$ & $\begin{array}{l}\text { TAATACGACTCACTATAATTGAAATCACTCCTTCC } \\
\text { TTAATTAAGATAAAAATTCTTAAAA }\end{array}$ & Template for Northern Blot probe \\
\hline $\begin{array}{l}\text { RNAIII NB } \\
\text { probe RV }\end{array}$ & $\begin{array}{l}\text { AGATCACAGAGATGTGATGGAAAATAGTTGATG } \\
\text { AGTTGTTTAATTTTAAGAATTTTTATC }\end{array}$ & Template for Northern Blot probe \\
\hline $\begin{array}{l}\text { 5SrRNA NB } \\
\text { probe FW }\end{array}$ & $\begin{array}{l}\text { TAATACGACTCACTATATAAGTTCGACTACCATCG } \\
\text { ACGCTAAGGAGCTTAACTTCTGTGT }\end{array}$ & Template for Northern Blot probe \\
\hline $\begin{array}{l}\text { 5SrRNA NB } \\
\text { probe RV }\end{array}$ & $\begin{array}{l}\text { TCTGGTGACTATAGCAAGGAGGTCACACCTGTTC } \\
\text { CCATGCCGAACACAGAAGTTAAGCTC }\end{array}$ & Template for Northern Blot probe \\
\hline $\begin{array}{l}\text { RNAIII PD } \\
\text { probe }\end{array}$ & CTTGTGCCATTGAAATCACTCCTTCCTT-biotin & Pull-down probe \\
\hline $\begin{array}{l}\text { 5SrRNA PD } \\
\text { probe }\end{array}$ & GGTGTGACCTCCTTGCTATAGTCACCAGA-biotin & Pull-down probe \\
\hline $\begin{array}{l}\text { RNAIII } \\
\text { template T7 } \\
\text { FW }\end{array}$ & $\begin{array}{l}\text { TAATACGACTCACTATAAGATCACAGAGATGTGA } \\
\text { TGG }\end{array}$ & Template for in vitro transcription \\
\hline $\begin{array}{l}\text { RNAllI } \\
\text { template RV }\end{array}$ & AAGGCCGCGAGCTTGG & Template for in vitro transcription \\
\hline
\end{tabular}




\begin{tabular}{|c|c|c|}
\hline $\begin{array}{l}\text { RNAIII DNA } \\
\text { enzyme I }\end{array}$ & $\begin{array}{l}\text { GTTCACTGTGGGCTAGCTACAACGACGATAATCC } \\
\text { AT }\end{array}$ & RNAIII cleavage by DNA enzyme \\
\hline $\begin{array}{l}\text { RNAIII DNA } \\
\text { enzyme II }\end{array}$ & $\begin{array}{l}\text { CGATAATCCAGGCTAGCTACAACGATTTACTAAG } \\
\text { TCA }\end{array}$ & RNAIII cleavage by DNA enzyme \\
\hline $\begin{array}{l}\text { RNAIII DNA } \\
\text { enzyme III }\end{array}$ & $\begin{array}{l}\text { CGATTGTTGAAAGGCTAGCTACAACGAGATATCT } \\
\text { TGTG }\end{array}$ & RNAIII cleavage by DNA enzyme \\
\hline RNAIII R1 & TGTTCACTGTGTCGATAATCC & cRT-PCR RNAIII \\
\hline RNAIII F1 & TCCTTGGACTCAGTGCTATG & cRT-PCR RNAIII \\
\hline RNAIII R2 & CACCGATTGTTGAAATGATATC & cRT-PCR RNAIII \\
\hline RNAIII F2 & GCTATCGTAAACAACATCGA & cRT-PCR RNAIII \\
\hline RNAII F1 & GTGGCAGTAATTCAGTGTATG & cRT-PCR RNAII \\
\hline RNAII R1 & GCATCCCTAATCGTACTTGC & cRT-PCR RNAII \\
\hline RNAII R2 & GATACGTGGCAAACTGGTC & cRT-PCR RNAII \\
\hline IS1 T7 FW & $\begin{array}{l}\text { TAATACGACTCACTATAATATGCTTTGTATGTTCA } \\
\text { CG }\end{array}$ & Template for RNA internal standard \\
\hline IS1 RV & CATTCTTTGCCTGTCAGAC & Template for RNA internal standard \\
\hline IS2 T7 FW & $\begin{array}{l}\text { TAATACGACTCACTATAAGCCACGTCACCTGTCCG } \\
\text { G }\end{array}$ & Template for RNA internal standard \\
\hline IS2 RV & $\begin{array}{l}\text { TAATACGACTCACTATAAGCCACGTCACCTGTCCG } \\
\text { G }\end{array}$ & Template for RNA internal standard \\
\hline IS3 T7 FW & $\begin{array}{l}\text { TAATACGACTCACTATAAGCGCCGTCGGGCGTTT } \\
\text { GGT }\end{array}$ & Template for RNA internal standard \\
\hline IS3 RV & GGCATATCCCTGGCGGGTGG & Template for RNA internal standard \\
\hline IS4 T7 FW & $\begin{array}{l}\text { TAATACGACTCACTATAACTATCTGAACCAAAATT } \\
\text { ATATC }\end{array}$ & Template for RNA internal standard \\
\hline IS4 RV & GGCATTAAGCAAATTTATC & Template for RNA internal standard \\
\hline $\begin{array}{l}\text { RNAllI-leader- } \\
\text { FW }\end{array}$ & $\begin{array}{l}\text { TAATACGACTCACTATAAGATCACAGAGATGTGA } \\
\text { TG }\end{array}$ & Template for in vitro transcription \\
\hline $\begin{array}{l}\text { RNAllI-leader- } \\
\text { RV }\end{array}$ & CCGATTGTTGAAATGATATC & Template for in vitro transcription \\
\hline SHAPE-RT1 & CTAAGTCACCGATTGTTGAAATG & Reverse transcription for RNAIII SHAPE \\
\hline
\end{tabular}


1133 Table S4: IS NAD-RNAs used for NAD captureSeq with their sequence.

\begin{tabular}{|c|c|}
\hline IS-RNA & RNA sequence \\
\hline IS 1 & AUAUGCUUUGUAUGUUCACGACGACCCGGGUCACGCACGCGGGUCUGACAGGCAAAGAAUG \\
\hline IS 2 & $\begin{array}{l}\text { AGCCACGUCACCUGUCCGGUAUCCAUCAGACUUUGCGCCAUCGGGCCGUUGUCGACGGAAUAAACCCAC } \\
\text { AUGUUGCGCUUCACCAGUUGGUAGGUCCAGCCGCC }\end{array}$ \\
\hline IS 3 & $\begin{array}{l}\text { AGUCAGAGCGUAGUCAGCAUGCUAACAAGCGGCUGGCACGAUUGCUGAUUGCCUGGAAGCUGGAGCAA } \\
\text { CAGCAACAGGAAAAUAGCGCGGCGCUGAAAUCGCAGCGGCGAAUGUUCCAUCACCAGAUUGAACGUGGC } \\
\text { AACCCGCGACGGACAUUUACAGGGAUGGCUUUUAUCGAAGGAUAAUGAAGGAUGAAACUGCCGGAAGG }\end{array}$ \\
\hline IS 4 & $\begin{array}{l}\text { AGCGCCGUCGGGCGUUUGGUCGCCCGCUCGAUUUUGUUUUCUACCGUGGUCUGAACGUCAGUGAAGCU } \\
\text { UCUGUACUGGUUACGCGCGCUUCCGAUCACAAUCCGCUACUCGUUGAAUUCAGUCCCGGCAAGCCUGAU } \\
\text { AAAUAAGGUAUGUCAGGUCUGCCACAGGGCAGACCAACGUUUGGCGCUGCGCAAAACGUGAGCGCGGU } \\
\text { GGUGGCGUAUGACUUAUCUGCCCACAUGCUGGAUGUCGUGGCACAAGCUGCCGAAGCCCGGCAACUGAA } \\
\text { AAAUAUCACCACCCGCCAGGGAUAUGCC }\end{array}$ \\
\hline IS 5 & $\begin{array}{l}\text { ACUAUCUGAACCAAAAUUAUAUCACAUUUCAGCAGGGUUAUUAUUUCUAUAAACCUGUUACAUACAUC } \\
\text { GACCUGGUCAAAAUUAUCCUUUCUAAACCGAAGGUGAAGGUUGUGGUUGAGUGAAAAUUGAUCAGUAA } \\
\text { GGCCAUAGUGCGGUGUAAUUAUAGACAGCUAAUUAGCUCGUUGCCUCUUGUUACUAUUGUUCAUUAU } \\
\text { UUUGUUUGCUAUAAUUGUUUGAAAGUUUUGACAGGAUUGCCAUUAGUAGCAUGAACAAUAGUAAUAA } \\
\text { UCUGGAUUAUUUCACUCUCUAUAUCAUAUUUUCCAUUGCAUUUAUGCUGAUCACCCUCCUGGUCAUCC } \\
\text { UUAUUGCAAAACCCAGUACCGGGCUGGGAGAAGUGCUUGUGACGAUAAAUUUGCUUAAUGCC }\end{array}$ \\
\hline
\end{tabular}


1135 Table S5: Enriched hits after NAD captureSeq in S. aureus pCG-P3 strain. Base mean: normalised 1136 mapped reads, Log2FC: Log2 Fold change (sample vs negative control). In bold are highlighted 1137 the common hits to S. aureus ATCC 25923 wild type strain (Table S2) and in regular font the non1138 common hits.

\begin{tabular}{|c|c|c|c|c|}
\hline Gene annotation number & Gene product & $\begin{array}{l}\text { Base } \\
\text { mean }\end{array}$ & Log2FC & $P$-value \\
\hline SAOUHSC_00086 & 3-ketoacyl-acyl carrier protein reductase putative & 60.65 & 2.49 & 0.000 \\
\hline SAOUHSC_00861 & Lipoyl synthase & 32.35 & 3.85 & 0.000 \\
\hline SAOUHSC_01685 & Heat-inducible transcription repressor HrcA & 127.01 & 2.84 & 0.000 \\
\hline SAOUHSC_02260 & Delta-hemolysin precursor/RNAIII & 5338.08 & 2.77 & 0.000 \\
\hline SAOUHSC_00467 & Pur operon repressor & 24.92 & 2.12 & 0.000 \\
\hline SAOUHSC_01191 & $50 S$ ribosomal protein L28 & 18.24 & 2.28 & 0.000 \\
\hline SAOUHSC_01432 & Peptide methionine sulfoxide reductase & 13.50 & 3.53 & 0.000 \\
\hline SAOUHSC_01493 & $30 \mathrm{~S}$ ribosomal protein S1 putative & 36.32 & 2.05 & 0.000 \\
\hline SAOUHSC_01997 & Peroxide-responsive repressor PerR & 28.14 & 2.07 & 0.000 \\
\hline SAOUHSC_02019 & Probable autolysin LytO & 203.90 & 2.52 & 0.000 \\
\hline SAOUHSC_02409 & Arginase & 13.34 & 5.09 & 0.000 \\
\hline
\end{tabular}


1140 Table S6: Enriched hits after NAD captureSeq in S. aureus pCG-P3(-1G) strain. Base mean: normalised mapped reads, Log2FC: Log2 Fold change (sample vs. negative control). In bold are

1142 highlighted the common hits to S. aureus ATCC 25923 wild type strain (Table S2) and in regular

1143 font the non-common hits.

\begin{tabular}{|c|c|c|c|c|}
\hline $\begin{array}{l}\text { Gene annotation } \\
\text { number }\end{array}$ & Gene product & Base mean & Log2FC & $P$-value \\
\hline SAOUHSC_00086 & 3-ketoacyl-acyl carrier protein reductase putative & 300.15 & 3.06 & 0.000 \\
\hline SAOUHSC_00781 & HPr kinase/phosphorylase & 31.15 & 3.96 & 0.000 \\
\hline SAOUHSC_01176 & Guanylate kinase & 12.58 & 2.53 & 0.000 \\
\hline SAOUHSC_01617 & Arginine repressor & 22.34 & 2.28 & 0.000 \\
\hline SAOUHSC_01685 & Heat-inducible transcription repressor HrcA & 184.56 & 2.50 & 0.000 \\
\hline SAOUHSC_02260 & Delta-hemolysin precursor & 16912.85 & 3.57 & 0.000 \\
\hline SAOUHSC_02577 & Putative 2-hydroxyacid dehydrogenase & 66.55 & 2.07 & 0.000 \\
\hline SAOUHSC_01191 & 50 S ribosomal protein L28 & 67.43 & 2.27 & 0.000 \\
\hline SAOUHSC_01653 & Superoxide dismutase 1 & 63.09 & 3.30 & 0.000 \\
\hline SAOUHSC_01981 & Sensor histidine kinase putative & 16.93 & 5.07 & 0.000 \\
\hline SAOUHSC_02019 & Probable autolysin LytO & 3110.21 & 3.23 & 0.000 \\
\hline SAOUHSC_02409 & Arginase & 26.68 & 3.04 & 0.000 \\
\hline
\end{tabular}


1145 Table S7: Enriched hits after NAD captureSeq in S. aureus pCG-P2 strain. Base mean: normalised 1146 mapped reads, Log2FC: Log2 Fold change (sample vs negative control). In blue are highlighted 1147 the common hits to S. aureus ATCC 25923 wild type strain (Table S2) and in green the non1148 common hits. Note that hld/RNAlll gene is not enriched in this table because due to its $+1 G$ 1149 condition.

\begin{tabular}{|l|l|r|r|r|}
\hline $\begin{array}{l}\text { Gene annotation } \\
\text { number }\end{array}$ & Gene product & Base mean & Log2FC & P-value \\
\hline SAOUHSC_00086 & 3-ketoacyl-acyl carrier protein reductase putative & $\mathbf{4 7 . 5 3}$ & $\mathbf{2 . 6 8}$ & $\mathbf{0 . 0 0 0}$ \\
\hline SAOUHSC_00861 & Lipoyl synthase & $\mathbf{1 6 . 3 4}$ & $\mathbf{3 . 3 0}$ & $\mathbf{0 . 0 0 0}$ \\
\hline SAOUHSC_01685 & Heat-inducible transcription repressor HrCA & $\mathbf{7 1 . 2 2}$ & $\mathbf{2 . 8 1}$ & $\mathbf{0 . 0 0 0}$ \\
\hline SAOUHSC_01191 & 50S ribosomal protein L28 & 17.10 & 2.11 & 0.000 \\
\hline SAOUHSC_01997 & Peroxide-responsive repressor PerR & 18.60 & 2.19 & 0.000 \\
\hline SAOUHSC_02019 & Probable autolysin LytO & 125.51 & 3.02 & 0.000 \\
\hline
\end{tabular}


1151 Table S8: pCG-P3 vs pCG-P3(-1G) transcriptomic analysis. Base mean: normalised mapped reads, 1152 Log2FC: Log2 Fold change (sample vs negative control). Negative Log2 Fold change values 1153 indicate downregulation, whereas positive values account for upregulated genes.

\begin{tabular}{|c|c|c|c|c|}
\hline Gene annotation number & Gene product & Base mean & Log2 Fold change & $P$-value \\
\hline SAOUHSC_00069 & Protein A & 94209.43 & -1.41 & 0.000 \\
\hline SAOUHSC_01938 & Serine protease SpID & 502.55 & 1.06 & 0.000 \\
\hline SAOUHSC_01939 & Serine protease SpIC & 547.92 & 1.15 & 0.000 \\
\hline SAOUHSC_01941 & Serine protease SplB & 584.74 & 1.19 & 0.000 \\
\hline SAOUHSC_01942 & Serine protease SpIA & 497.76 & 1.12 & 0.000 \\
\hline SAOUHSC_02576 & Secretory antigen precursor SsaA putative & 560.25 & -1.28 & 0.000 \\
\hline
\end{tabular}

1154 
bioRxiv preprint doi: https://doi org/10,1101/778233; this version posted September 24, 2019. The copyright holder for this preprint (which was not certified by peer review) is the author/funder, who has granted bioRxiv a license to display the preprint in perpetuity. It is made available under aCC-BY-NC-ND 4.0 International license.

1155 Table S9: Bacterial strains used in this study

Bacterial strain

Staphylococcus aureus subsp. aureus ATCC 25923

Escherichia coli $\mathrm{K}-12$

Staphylococcus aureus subsp. aureus RN4220

Staphylococcus aureus subsp. aureus HG001

Staphylococcus aureus subsp. aureus HG001 $\triangle$ RNAIII

Staphylococcus aureus subsp. aureus HG001 $\Delta R N A I I I, \Delta p s m \alpha B$

Staphylococcus aureus subsp. aureus HG001 $\triangle$ RNAIII pCG-P3

Staphylococcus aureus subsp. aureus HG001 $\triangle$ RNAIII pCG-P2

Staphylococcus aureus subsp. aureus HG001 $\triangle$ RNAIII pCG-P3(-1G)

\section{Source}

American Type Culture Collection (ATCC)

Lab strain collection

Charpentier et al., 2004

Herbert et al., 2010

This study

This study

This study

This study

This study 
bioRxiv preprint doi: https://doi.org/10.1101/778233; this version posted September 24, 2019. The copyright holder for this preprint (which was not certified by peer review) is the author/funder, who has granted bioRxiv a license to display the preprint in perpetuity. It is made available under aCC-BY-NC-ND 4.0 International license.

A

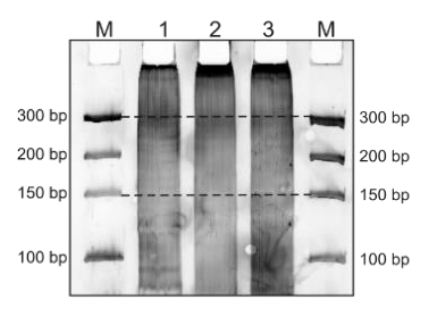

B

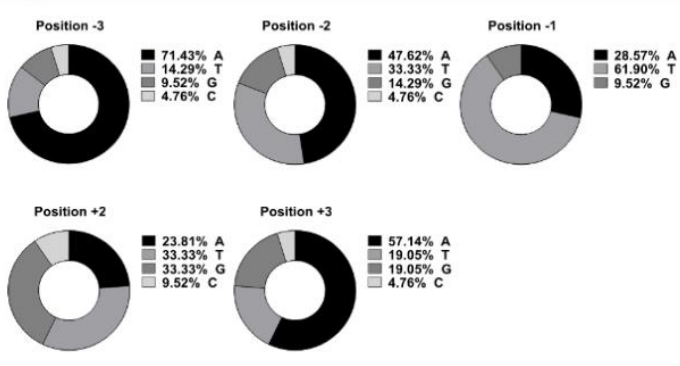

C

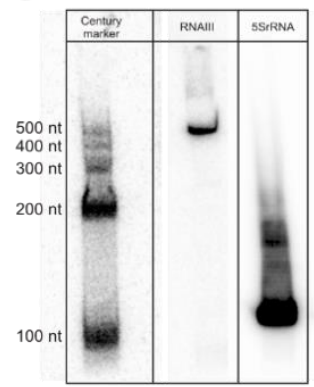

D

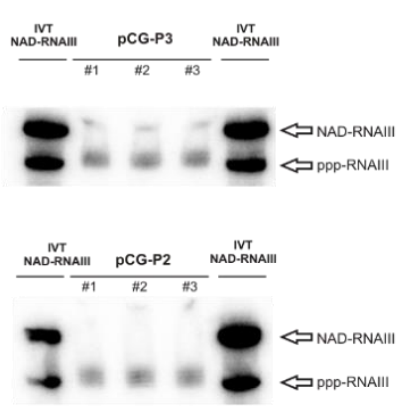

E

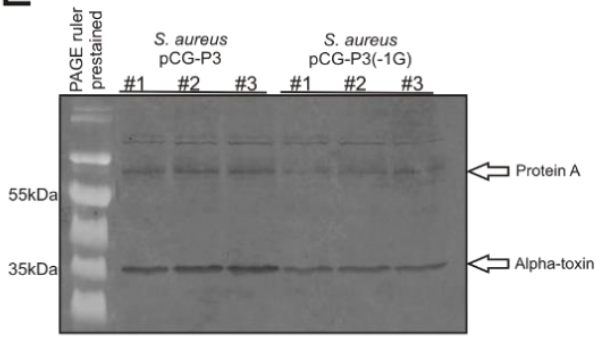

$\mathrm{H}$
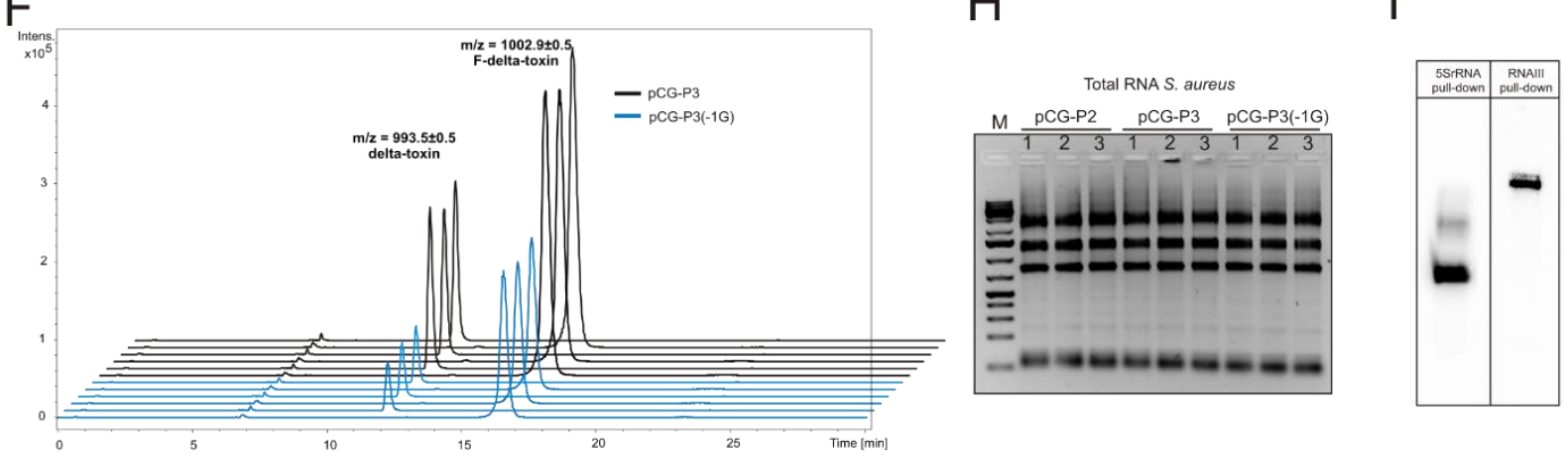

G

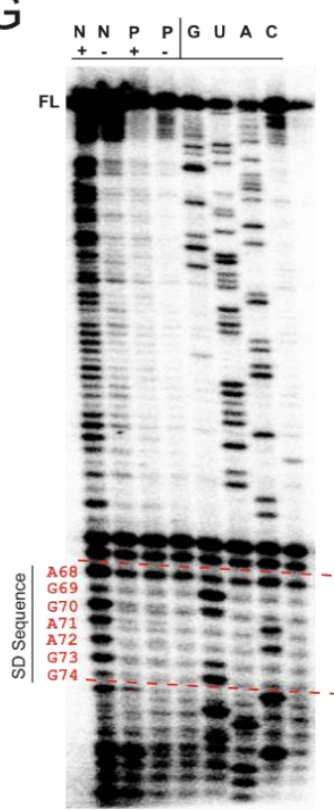

J

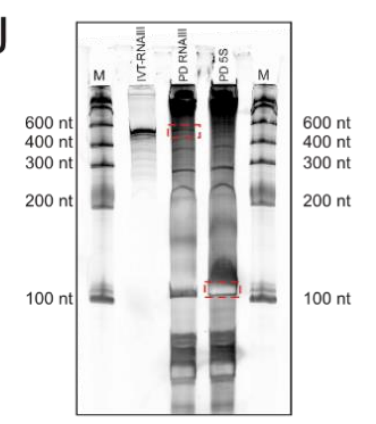

L
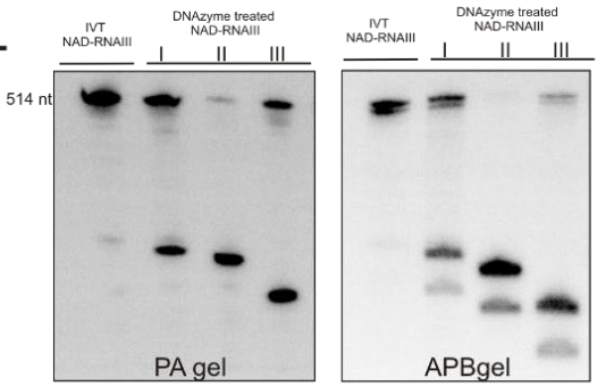

K

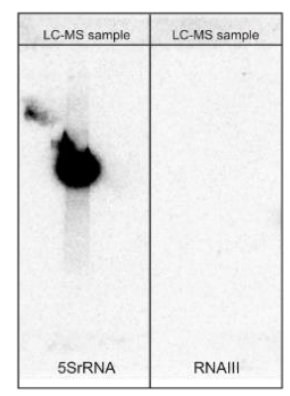

M

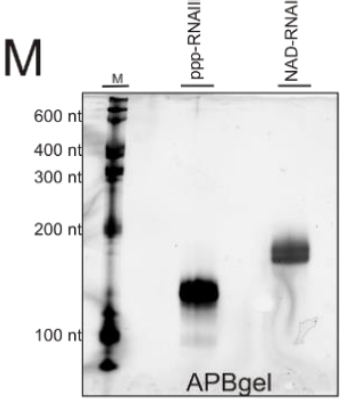

Figure S1 
bioRxiv preprint doi: https://doi.org/10.1101/778233; this version posted September 24, 2019. The copyright holder for this preprint (which was not certified by peer review) is the author/funder, who has granted bioRxiv a license to display the preprint in perpetuity. It is made available under aCC-BY-NC-ND 4.0 International license.

$1161 \quad 15$ 